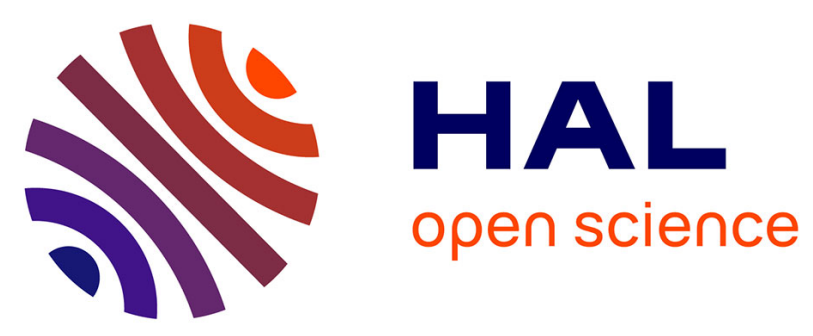

\title{
Impact of intra-category food substitutions on the risk of type 2 diabetes: a modelling study on the pizza category
}

\author{
Moufidath Adjibade, François Mariotti, Pascal Leroy, Isabelle Souchon, Anne
}

Saint-Eve, Guy Fagherazzi, Louis-Georges Soler, Jean-François Huneau

\section{- To cite this version:}

Moufidath Adjibade, François Mariotti, Pascal Leroy, Isabelle Souchon, Anne Saint-Eve, et al.. Impact of intra-category food substitutions on the risk of type 2 diabetes: a modelling study on the pizza category. British Journal of Nutrition, In press, 10.1017/s0007114521002130 . hal-03355131

\section{HAL Id: hal-03355131 \\ https://hal.science/hal-03355131}

Submitted on 27 Sep 2021

HAL is a multi-disciplinary open access archive for the deposit and dissemination of scientific research documents, whether they are published or not. The documents may come from teaching and research institutions in France or abroad, or from public or private research centers.
L'archive ouverte pluridisciplinaire HAL, est destinée au dépôt et à la diffusion de documents scientifiques de niveau recherche, publiés ou non, émanant des établissements d'enseignement et de recherche français ou étrangers, des laboratoires publics ou privés. 
Impact of intra-category food substitutions on the risk of type 2 diabetes: a modelling study on the pizza category

Moufidath Adjibade ${ }^{1}$, François Mariotti ${ }^{1}$, Pascal Leroy ${ }^{2}$, Isabelle Souchon ${ }^{3}$, Anne Saint-Eve ${ }^{3}$, Guy Fagherazzi ${ }^{4,}$, Louis-Georges Soler ${ }^{2}$, Jean-François Huneau ${ }^{1}$

${ }^{1}$ Université Paris-Saclay, AgroParisTech, INRAE, UMR PNCA, 75005, Paris, France

${ }^{2}$ UR 1303 ALISS, INRAE, Ivry sur Seine, France

${ }^{3}$ Université Paris-Saclay, INRAE, AgroParisTech, UMR SayFood, 78850, Thiverval-

Grignon, France

${ }^{4}$ Digital Epidemiology Hub, Department of Population Health, Luxembourg Institute of Health, Luxembourg,

${ }^{5}$ UMR CESP, Inserm, Institut Gustave Roussy, Université Paris Sud, Université Paris-Saclay, France

PubMed indexing: Adjibade, Mariotti, Leroy, Souchon, Saint-Eve, Fagherazzi, Soler, Huneau

Corresponding author: Prof. François MARIOTTI, 16 rue Claude Bernard, 75005 Paris, France, francois.mariotti@agroparistech.fr.

Running title: Pizza substitutions and risk of type 2 diabetes

\section{Abbreviations:}

ANSES: Agence nationale de sécurité sanitaire de l'alimentation, de l'environnement et du travail (French Agency for Food, Environmental and Occupational Health Safety)

BMI: Body mass index

CIQUAL: Centre d’Information sur la Qualité des Aliments (Food Quality Information Center)

CNIL: Commission Nationale de l'Informatique et des Libertés (French National Commission for Computed Data and Individual Freedom)

FP: Food Pattern

HAC: Hierarchical Ascending Classification 
IDF: International Diabetes Federation

IE substitution: Isoenergetic substitution

INCA2: Etude Individuelle Nationale des Consommations Alimentaires 2 (second Individual and National Food consumption survey)

MEDI-LITE: Literature-Based Adherence Score to the Mediterranean Diet

mPNNS-GS: version modifiée du Programme National Nutrition Santé Guideline Score (modified version of the French National Nutrition Health Program)

NCD: Non-Communicable Disease

NIE substitution : Non-isoenergetic substitution

Oqali: Observatoire de la qualité de l'alimentation (French food quality observatory)

PCA: Principal Component Analysis

PRIME: Preventable Risk Integrated ModEl

T2D: Type 2 Diabetes 

(1) (2)

\section{ABSTRACT}

Advice on replacing unhealthy foods with healthier alternatives within the same food category may be more acceptable and might ease the transition towards a healthy diet. Here, we studied the potential impact of substitutions within the pizza category on the risk of type 2 diabetes (T2D). The study sample consisted of 2,510 adults from the INCA2 French national survey. Based on their nutritional characteristics, the 353 pizzas marketed in France were grouped in 100 clusters that were used to run various scenarios of pizza substitutions, which were either isoenergetic (IE) or non-isoenergetic (NIE). We then used a model structurally similar to the Preventable Risk Integrated ModEl (PRIME) to assess the expected rate of change in risk of T2D. Pizzas characterized by a low energy, high vegetable content and whole grain dough were associated with a greater reduction in the risk of T2D. The rates of change in risk of T2D were markedly stronger in men and for NIE substitutions. When the rates of change were estimated in the subsample of pizza consumers, replacing the observed pizzas with the best pizza resulted in a T2D risk reduction of $-6.7 \%(-8.4 \%$; $-4.9 \%$, IE) and $-8.9 \%(-11.2 \% ;-6.3 \%$, NIE), assuming that this is their usual diets. The greatest risk reduction induced by an IE substitution of the observed pizza with a mixed dish was similar to that observed with the best pizzas. Overall, this modelling study suggests that healthy swaps within a category can effectively supplement broader dietary changes toward a healthier diet.

Keywords: Food substitutions: Pizza categories: Type 2 diabetes: Public health 


\section{INTRODUCTION}

Diabetes is one of the most challenging public health issues, with a prevalence that is steadily increasing worldwide (1). According to the International Diabetes Federation (IDF), the number of people with diabetes is expected to rise from 425 million in 2017 to 629 million in 2045 (2). Diabetes can lead to long-term complications, including coronary heart disease, kidney disease, stroke, eye disease and neurological damage, and increase the overall risk of premature death. It has a considerable health-care cost and significantly impacts quality of life $(1,3-5)$.

Type 2 diabetes (T2D) is the most common type of diabetes. Epidemiological studies suggest that a combination of non-modifiable risk factors (such as age, ethnicity and genetics) and modifiable risk factors (including physical inactivity, unhealthy diet, excess body weight and tobacco use) are contributors to the development of T2D (6,7). According to current scientific evidence, eating a healthy diet, having a high level of physical activity and avoiding smoking could prevent up to $80 \%$ of type 2 diabetes cases $(8,9)$. Regarding the T2D risk, several epidemiological studies have shown negative associations for healthy diets (characterized by a high consumption of plant-based foods, whole grain products, fish and olive oil) ensuring an adequate intake of various vitamins and minerals, and positive associations for unhealthy diets (characterized by a high consumption of red and processed meats, refined grains, and foods high in sugars, saturated fats or trans fats) (10-12). Mediterranean and vegetarian diets have been shown to be particularly beneficial (13-15).

An overall healthy dietary pattern is the core objective for populations in public health nutrition, but because changing overall dietary patterns is an overwhelming task, guidelines have increasingly focused on making healthy choices within the different food groups as a practical method for implementation (16). More specifically, choosing a healthier alternative within a food category may be more readily achievable than substituting foods between different categories. However, to our knowledge, the efficiency of within-category substitutions on reducing the risk of T2D has not been evaluated to date.

The aim of this study was therefore to evaluate the potential impact of pizza substitutions on the risk of T2D as compared to substitutions by foods from the different category of mixed dishes, and to identify the characteristics of pizzas related to a stronger reduction in the risk of T2D. We also wanted to examine whether the impact of tailored substitutions, i.e. implementing a substitution based on an individual dietary risk assessment differed from that 
of generic substitution, i.e. the same substitution for all individuals. The pizza category (generally classified as unhealthy) was selected for the present study because of the considerable nutritional variability in this category and its relatively high consumption (17).

\section{MATERIALS AND METHODS}

\section{Study Population}

Our analyses were based on the second Individual and National Food consumption survey (INCA2) conducted in 2006-2007 by the French Agency for Food, Environmental and Occupational Health Safety (agence nationale de sécurité sanitaire de l’alimentation, de l'environnement et du travail, ANSES) to assess dietary intake and associated behaviors in a nationally representative sample of the French population $(18,19)$. The survey included two home visits by trained investigators. The INCA2 survey has been approved by the French National Commission for Computed Data and Individual Freedom (Commission Nationale de l’Informatique et des Libertés, CNIL) (18).

In the present study, participants aged 3-17 years $(n=1,455)$ were excluded from the initial INCA2 sample $(n=4,079)$. Under-reporters defined as participants who reported a daily energy intake of less than $1000 \mathrm{Kcal}(\mathrm{n}=114)$ were also excluded. The final sample therefore included 2,510 participants (57.1\% women) aged 18-79 years (Supplemental Figure 1).

\section{Data collection}

Socioeconomic, demographic and physical activity data were collected during face-to-face interviews. Regarding physical activity, the short form of the French version of the International Physical Activity Questionnaire (20) was used to estimate energy expenditure in metabolic equivalents, expressed in MET-min per week. Trained investigators also collected weight and height data and body mass index (BMI) was calculated as the ratio of weight to squared height $\left(\mathrm{kg} / \mathrm{m}^{2}\right)$.

\section{Dietary data}

Dietary intake was assessed using 7-day food records (18). During the survey week, the participants were asked to report all foods and beverages consumed at each meal. Portion sizes were estimated using validated photographs (21), household measurements or by specifying the exact amount consumed.

In order to obtain a precise estimate of the consumption of each food group identified as having an impact on the risk of T2D (whole grains, refined grains, fruits, green leafy 
vegetables, other vegetables, nuts, potatoes, dairy products, red meats, fish, eggs, processed meats, butter, olive oil, tea, coffee, chocolate, sugar-sweetened beverages, alcoholic beverages) $(12,22-29)$, each item reported by the participants was broken down into its ingredients (expressed as a quantity). The daily intake of energy and certain nutrients (carbohydrates, dietary fibers and magnesium) associated with the risk of T2D (30-32) were also estimated for each participant using CIQUAL (Centre d'Information sur la Qualité des Aliments) food composition tables. Other nutrients associated with the risk of T2D, such as polyphenols (33) were not considered in our study because the data were not available.

\section{Pizza composition and classification}

We used the database from the “Observatoire de la qualité de l'alimentation” (Oqali), which collects labelling information on foods marketed in France, to estimate the nutrient composition and proportions of ingredients in the 353 pizza recipes (data collected in 2011) sold by medium and large supermarkets and frozen food stores. These 353 pizzas presented considerable diversity in terms of their nutritional quality, which was dependent on numerous criteria, such as the pizza family (cheese, vegetarian, ham-cheese, etc.), ratio of animal/plant ingredients or the quantity of dough.

These pizzas were grouped into 100 clusters based on their recipes and nutritional composition using a hierarchical ascending classification (HAC). First, a principal component analysis (PCA) was performed using the quantities of the main ingredients and the nutritional composition of the pizzas as input variables. The HAC using Ward's step method was then performed for the first 4 factors resulting from the PCA (54\% of the total variance explained). In order to keep a good picture of the large variability in the composition of the pizza category, the number of clusters at the end of the HAC was set at 100. For each cluster, the mean recipe and nutritional composition were determined and an "average” pizza

(Supplemental Table 1) was therefore used for the pizza substitutions.

\section{Statistical analysis}

Baseline characteristics are presented separately for pizza consumers (participants who reported pizza consumption at least once during the 7-day food records) and non-consumers using means and standard deviation for continuous variables and percentages for categorical variables. Pizza consumers were compared to non-consumers using chi2 tests or t-tests as appropriate. 


\section{Estimation of the rate of change in the risk of type 2 diabetes}

The rate of change in the risk of T2D was estimated using a model structurally similar to the Preventable Risk Integrated ModEl (PRIME). PRIME is a scenario model that estimates the impact of lifestyle changes in the population (diet, alcohol / tobacco consumption, BMI and physical activity) on non-communicable disease (NCD) mortality $(34,35)$. Briefly, the PRIME estimates the change in the annual number of NCD deaths between the baseline and counterfactual scenarios that depends on changes in the distribution of one or more behavioral risk factors in the study population. The model is parameterized using meta-analyses of epidemiological studies providing estimates of relative risks (RR) linking diet and lifestyle variables and disease outcomes.

Using comparative risk assessment to estimate the rate of changes in T2D risk consists in estimating $\left(\mathrm{x}^{\prime}-\mathrm{x}\right) / \mathrm{x}$, where $\mathrm{x}$ is the observed baseline incidence resulting from the initial distribution of risk factors and $x$ ' the counterfactual situation resulting from changes in risk factors. Here, we set $x=1$, resulting in a rate of change in risk being equal to $\mathbf{x}^{\prime}-1$, which is thus the relative change (expressed as \%) in risk.

If referring to the classical framework of the Comparative Risk Assessment on which the PRIME model is based (35), this rate of change in risk for each factor (i.e. nutritional variable) is the final Population Attributable Fraction (PAF) ascribed to this factor. The PAF for the different risk factors 1 to $n$ for the same disease are then combined multiplicatively in the PRIME model (PAFtot).

$$
P A F=\left[\int R R(q) P(q) d q-\int R R(q) P^{\prime}(q) d q\right] / \int R R(q) P(q) d q
$$

and

$$
\text { PAFtot }=1-\prod_{i=1}^{n}\left(1-P A F_{i}\right)
$$

where $\mathrm{RR}(\mathrm{q})$ is the relative risk of disease for risk factor level q (i.e. the level of intake for the nutritional variable), $P(\mathrm{q})$ is the number of people in the population with risk factor level $\mathrm{q}$ in the baseline scenario, and $P^{\prime}(q)$ is the number of people in the population with risk factor level $\mathrm{q}$ in the counterfactual scenario.

With this background, the rate of change in risk as estimated in the present study therefore refer to -PAFtot. 
In this study, we estimated the rate of change in the risk of T2D that would result from pizza substitutions (i.e. how much the risk of T2D varies when varying the intake of dietary factors (food groups and nutrients in the diet as affected by the pizza substitution). The model parameterization does not require data regarding the mortality nor the diabetes incidence in the population, and the latter was anyway not reliably available for France. Model parameterization was achieved using recently published RR data on the dose-response associations between diet (food groups and nutrients previously mentioned) and the risk of T2D (12,22-28,30-32) as shown in Supplemental figure 2. The macrosimulation model also requires the baseline distributions of the various nutritional variables that are risk factors (sexspecific distributions for each food group and nutrient in the study population before pizza substitution) and the counterfactual distributions (sex-specific distributions for each food group and nutrient after pizza substitution).

Monte Carlo simulations (10,000 iterations) were performed to estimate 95\% credible intervals around the estimates (2.5th percentile; 97.5th percentile).

Given the strong association between BMI (and therefore energy intake) and the risk of T2D, both isoenergetic (IE) and non-isoenergetic (NIE) substitutions were considered. The IE substitution consisted in replacing the observed pizza with the same weight of another pizza, while maintaining energy intake constant, by homogeneously adjusting the weight of all the other solid foods consumed. The NIE substitution only consisted in replacing the observed pizza with the same weight of another pizza without maintaining energy intake.

The macrosimulation model algorithm was implemented in R. All other statistical analyses were conducted using SAS (version 9.4; SAS institute Inc., Cary, NC, USA) with a significance level of 0.05 for two-sided tests.

\section{Pizza substitutions}

The substitutions were first performed at the individual level in order to identify for each participant the best/worst pizzas. To do this, each individual was artificially over-represented (so that it represents half of the overall population) so as to achieve sufficient precision in the estimate and thereby enabling easy individual ranking of the pizzas. The rates of change in the risk of T2D attributable to the various pizza substitutions were then ranked in ascending order to identify the pizzas leading to the highest relative increase (worst pizzas) or decrease (best pizzas) in the risk of T2D. 
Second, we made three different types of pizza substitutions in pizza consumers in the overall sample. These substitutions consisted in simultaneously replacing the observed pizza by: 1) each of the five best/worst pizzas specific to the individual (tailored substitution); 2) the pizzas most frequently identified as the best or worst by all consumers (generic substitution) and 3) all the 68 mixed dishes identified in the INCA food database (generic substitution; Supplemental Table 2). Generic substitutions were analyzed by considering either the overall sample study (i.e. pizza consumers and non-consumers) or the subsample of pizza consumers (all pizza consumers, as well as consumer sub-groups created according to their observed pizza consumption level), or other subgroups based on age, fruit and vegetable consumption, BMI and the overall diet quality.

Diet quality was measured using three dietary scores, namely the Literature-Based Adherence Score to the Mediterranean Diet (MEDI-LITE), the provegetarian food pattern (FP) and the modified version of the French National Nutrition Health Program (Programme National Nutrition Santé Guideline Score, mPNNS-GS). The mPNNS-GS, MEDI-LITE and provegetarian FP had respectively been developed to measure adherence to French nutritional guidelines, adherence to the Mediterranean diet and preferences for plant-derived foods (3639). The description and scoring systems for these dietary scores are presented in

\section{Supplemental Figure 3.}

\section{RESULTS}

The analyses included 1,076 men and 1,434 women aged $46.6 \pm 15.5$ and $45.2 \pm 15.2$ years respectively. Among the 880 pizza consumers, 78.2\% reported pizza consumption once during the food data collection week and $16 \%$ twice. Compared to non-consumers, pizza consumers were more likely to be men, younger people, living alone, smokers, students or people in employment. They were also more likely to have a higher level of education (high school diploma or university level), a normal BMI and a low consumption of fruits and vegetables (<400g/day) (Table 1).

We used the pizza ranking results specific to each individual to identify the best pizzas to be used for generic substitutions. Only four pizzas resulted in the highest risk reduction in at least one consumer. In IE substitutions, pizza clusters \#88, \#99, \#22 and \#100 were identified as the best pizzas for $96.6 \%, 1.6 \%, 0.9 \%$ and $0.9 \%$ of pizza consumers, respectively

(Supplemental Table 1). These four clusters were characterized by a high proportion of vegetables (including green leafy vegetables for cluster \#100) and a whole grain dough 
(except the cluster \#100). Clusters \#88 and \#100 were also identified as the best pizzas in NIE substitutions for $99.9 \%$ and $0.1 \%$ of pizza consumers, respectively (Supplemental Table 1). Regarding the worst pizzas, the clusters identified (clusters \#78 and \#84 for both IE substitutions and NIE substitutions) were characterized by a low proportion of vegetables and a high proportion of processed meat (Supplemental Table 1).

Tailored and generic pizza substitutions in the whole population resulted in rates of change in the risk of T2D in the range of $-3.6 \% ;+5.2 \%$ (Figure 1). Overall, the rates of change were stronger in men and for NIE substitutions. For IE substitutions, replacing each consumer's pizza with one of his/her five best pizzas (tailored substitution) led to a population-wide reduction in the risk of T2D that ranged from $-2.6 \%(-3.3 \% ;-1.9 \%)$ to $-2.0 \%(-2.5 \% ;-1.4 \%)$ in men, and $-1.4 \%(-1.8 \% ;-1.0 \%)$ to $-1.1 \%(-1.4 \% ;-0.7 \%)$ in women. Symmetrically, changing for one of the five worst pizzas led to an increased risk of T2D that ranged from $2.6 \%(1.8 \% ; 3.4 \%)$ to $1.1 \%(0.7 \% ; 1.5 \%)$ among men and $1.3 \%(0.9 \% ; 1.7 \%)$ to $0.6 \%(0.4 \%$; $0.8 \%$ ) among women. The beneficial/detrimental estimated impacts of tailored substitutions decreased significantly between the first and third best/worst pizzas and only slightly thereafter.

For generic substitutions (using the pizzas most frequently identified as the best/worst), only pizzas identified as such for both IE and NIE substitutions (clusters \#88 and \#100 for the best pizzas and clusters \#78 and \#84 for the worst pizzas) were considered. The IE substitution of the observed pizzas for one of these four pizzas resulted in rates of change in the risk of T2D that ranged from $-2.6 \%(-3.3 \%$; $-1.9 \%)$ to $+2.6 \%(1.8 \%$; 3.4\%) in men (Figure 1). Overall, the greatest reduction was achieved with cluster \#88 for both IE and NIE substitutions. In addition, generic substitutions (Figure 1, lower panel) showed similar rates of change in the risk of T2D that were similar to those observed for tailored substitutions (Figure 1, upper panel).

For both IE and NIE substitutions, the rates of change in the risk of T2D were more pronounced when estimated in the pizza consumers sub-sample, with a rate of change that increased in line with the frequency of pizza consumption (Table 2). Regarding the rates of change in the risk of T2D among other population subgroups, the most important changes were generally observed among younger participants (Supplemental Table 3). 
Inter-category substitutions resulted in rates of change in the risk of T2D for the whole population that ranged from $-5.4 \%$ to $+9.5 \%$ (Figure 2 ). We identified one best mixed dish (pan bagnat for IE substitutions and spaghetti with tomato sauce for NIE substitutions) and one worst mixed dish (hotdog, for both IE and NIE substitutions). For IE substitutions, no replacement with a mixed dish led to a greater reduction in T2D than that observed when replacing with the best pizza, unlike NIE substitutions where a few mixed dishes allowed greater risk reductions than those observed with the best pizzas. For both IE and NIE substitutions, we found that some mixed dishes had a markedly stronger rates of change in the risk of T2D than the worst pizzas identified in this study. The best / worst mixed dishes were the same in the different population subgroups, except in the case of NIE substitutions where the best mixed dish was spaghetti with tomato sauce for some subgroups and spring rolls for others (Supplemental Table 4).

\section{DISCUSSION}

To our knowledge, this is the first study to have investigated the potential impact of food substitutions within the same category on the risk of T2D. In this modeling study based on food records collected on a large representative sample of the French population, we found that substitutions within the pizza category showed high rates of change in the risk of T2D when the recipe included several ingredients with a documented impact on T2D.

The best pizzas identified in this study contained high levels of plant-based ingredients and had a whole grain dough. Most of them had a low energy density and contain large quantities of fiber and magnesium. Despite the large number of pizzas containing a high proportion of vegetables, only four were identified as the first best for IE substitutions. These findings could be explained by the fact that all vegetables have a low and borderline beneficial impact on the risk of T2D (RR=0.98; 95\% CI=0.96-1.00) (12). Overall, the food groups included in PRIME that are considered to have a strong impact on the risk of T2D are: whole grains $(\mathrm{RR}=0.87$; 95\% CI=0.82-0.93), green leafy vegetables $(R R=0.87 ; 95 \% \mathrm{CI}=0.76-0.99)$ and olive oil $(\mathrm{RR}=0.91 ; 95 \% \mathrm{CI}=0.87-0.95)(12,29)$. Indeed, whole grains are an important source of phytochemicals and other nutrients such as vitamins B and E, cereal fiber, zinc and magnesium (40-42). The regular consumption of whole grains (particularly high-fiber cereals) has been associated with greater insulin sensitivity and lower fasting insulin levels. Eating plenty of whole grains may also reduce the risk of T2D by lowering levels of inflammatory markers, including C reactive protein and Interleukin-6 (43). As for green leafy vegetables, their beneficial impacts have been attributed to their low carbohydrate content and 
antioxidant and anti-inflammatory properties (29). Our modeling study could provide final risk estimates regarding the potential impact of modulating these ingredients in the recipe of a food item found to be consumed by the population.

For both pizzas and the other dishes, NIE substitutions showed higher rates of change in the risk of T2D than IE substitutions. Indeed, based on data from meta-analyses (12,22-28,3032), our model was parameterized so that an increase in energy intake resulted in an increased T2D risk, as a function of the BMI and level of physical activity of the subjects. Under this model, a change in energy intake is an important factor for risk estimates, in line with the importance of energy imbalances in being overweight and of being overweight in the T2D risk, as highlighted in the literature (44). However, although energy density and portion size are key drivers of a long-term energy imbalance, mechanisms for adjustment to subsequent energy intake should partly buffer the impact of a difference in energy content between two dishes on long-term energy intake. Therefore, the final impact of a substitution is expected to be somewhere between the impacts of IE and NIE substitutions.

More specifically, we found that the rates of change in the risk for IE and NIE pizza substitutions were more pronounced when the substitution resulted in an increase in risk, and very small when it resulted in a decrease. This could be explained by the fact that when pizzas contain a highly adverse pattern of ingredients they are also higher in energy. Conversely, only two of the four best pizzas identified for IE substitutions remained the best when used for NIE substitutions, apparently because their energy content is not particularly high. Differences in energy content could also explain the switch in the order of the two worst pizzas, depending on whether they were used for IE or NIE substitutions.

In this study, the rates of change in the risk of T2D attributable to the various pizza substitutions observed in the whole population may appear to be small. In contrast, rates of change in the risk of T2D were higher for NIE substitutions and when estimated in the pizza consumers sub-sample, with a rate of change that increased in line with the frequency of pizza consumption. The small range observed for the rates of change in the risk of T2D could first be explained by the fact that only one food category was replaced, while a diet consists of several meals and therefore several food categories. Secondly, not all participants in this study consumed pizza during the food data collection period. In addition, pizza was consumed in relatively small portions (particularly among women, with an average portion size of $187 \mathrm{~g}$ for women compared to $262 \mathrm{~g}$ for men) and approximately $78 \%$ of pizza consumers ate it 
only once during the food record week. Intra-category substitutions applied simultaneously to several food categories would lead to much greater reductions in the T2D risk. We had previously reported that extended and repeated intra-category substitutions can drive very marked healthy changes in nutrient intakes in the whole population (45). Here, we once again showed that rates of change in risk for NIE substitutions in the population of men consuming pizzas more than twice per week could reach $-18 \%$ and $+32 \%$.

The findings of this study show that tailored substitutions do not have a greater impact than generic substitutions with pizzas that have been identified as the best. This was explained by the fact that the first best pizza (cluster \#88) was the same for almost all pizza consumers (96.5\%). Cluster \#88 differed from the other clusters by its low energy content and high whole grain content. Interestingly, substitutions at the individual level showed that if cluster \#88 were set aside, the second best pizza (cluster \#100) was the same for a large majority (76\%) of pizza consumers. This second best pizza enabled a reduction in the T2D risk close that obtained with cluster \#88, with a different recipe, as it included green leafy vegetables but not whole grains. Taken together these results of intra-category substitutions showed that the dietary levers for reducing the T2D risk proved to be the same for the vast majority of the population, which makes tailored advice useless. Although pizzas present a broad diversity of composition, we cannot generalize this finding to all food categories.

Quite unexpectedly, we failed to identify a mixed dish that induced a greater reduction in the risk of T2D than the best pizza in IE substitution. This may have been due to the fact that although we considered a broad range of dishes $(n=68)$, their recipes included no or only a tiny proportion of ingredients from the food groups with the most favorable expected impacts on the risk of diabetes. The best mixed dish identified for IE substitutions had nutritional characteristics similar to those of the best pizza, i.e. high in fiber and magnesium. Regarding NIE substitutions, the greatest estimated T2D risk reduction achieved with mixed dishes such as spaghetti or spring rolls compared to the best pizza was not due to their higher proportion of healthy ingredient, but to their lower energy density. Overall, these results showed that substitutions within a category can have a considerable impact on the T2D risk since it was comparable to substitutions between categories.

In this study, our estimates were not translated into numbers of avoided incident cases of T2D, because we do not have valid direct estimates of diabetes incidence in France in the entire adult population (46). However, based on available data, we may consider that T2D 
incidence might be in the order of 500 per 100,000 person year in men and 350 per 100.000 person in women. If using data from table 2 showing rates of changes in risk of diabetes in men and women for substitution with the best and worst pizzas, and if considering that the effect would lie in between that of iso-energetic substitution and non-isoenergetic substitutions, the substitutions might result in between 6700 and 9400 new cases of diabetes avoided each year in France.

This modelling study has some potential limitations that should be mentioned. First, parametrization of our model is limited by the availability of robust meta-analyses estimating RR values for associations between lifestyle indicators and health outcomes. Indeed, most of the available RR have been estimated for the general population, while for some factors, the estimated risks may vary as a function of socio-demographic and health characteristics. In addition, in the absence of reliable information, we considered that the initial risk of T2D was the same for all the population subgroups examined in our study. Further, some nutritional factors such as polyphenols, cholesterol and zinc, among others, could not be included in the model, either because their relation to T2D risk has not been sufficiently characterized or due to lack of detailed data on their contents in different foods. Another limitation of this study is that it cannot be excluded that the relative risks used in the parameterization of the model may vary slightly according to the population groups considered and this may have added some uncertainty on the estimates of risk changes drawn on this population.

In this study, some participants had missing data on some variables, but BMI is the only one that is used in the risk assessment model. The missing values that could have an impact on the model are limited to 2 missing BMI values among the 878 pizza consumers for whom nonisoenergetic substitutions were run.

Some important strengths of this study include its large sample size (with approximately 35\% of pizza consumers), the quality of the dietary data based on 7-day food records that reflected the actual dietary habits of the participants as well as that of anthropometric data because they were taken by trained investigators. Another strength is the availability of a large database including recipes of more than 300 pizzas marketed in France, which was useful to exploring all possibilities in a realistic way.

In conclusion, the results of this study suggest that substitutions within the pizza category are associated with modest reduction in T2D risk, with a rate of change that increased in line with the frequency of pizza consumption, justifying the promotion of a healthier swap, as it is 
374 increasingly advocated in dietary guidelines. Our results also suggest that substitutions within

375 the same category might be particularly effective inasmuch as in principle they are easier to

376 implement than the total exclusion of a food category and could play a role in achieving a

377 generally better dietary pattern. For these theoretical results to work in practice, the messages

378 would of course need to be accompanied by a radical transformation of the food offer that

379 takes account of sensory acceptability. The results of this article remain theoretical and are

380 based on comparative risk assessment on modelled diets. They would need to be corroborated

381 in long-term interventional studies, assessing the effects of limited and well-defined dietary

382 changes on endpoints related to diabetes risk.

\section{Acknowledgements}

384 This study was supported by a grant from Université Paris-Saclay (Nutriperso project).

385 The author contributions were as follows: F.M., L.-G.S. and J.-F.H. designed the study; I.S.

386 and A.S.-E. supplied the databases essential for the research; G.F. and P.L. provided

387 methodological support; M.A. and P.L. analyzed the data. M.A., F.M., P.L. and J-F.H

388 interpreted the results; M.A. wrote the first draft of the manuscript; F.M. and J.-F.H.

389 contributed to writing the manuscript; all authors provided critical comments on the

390 manuscript. All authors read and approved the final manuscript.

391 None of the other authors declare any conflicts of interest. 


\section{References}

1. World Health Organization. Global report on diabetes. WHO: France (2016).

2. International Diabetes Federation. IDF Diabetes Atlas, 8th edn. Brussels, Belgium: International Diabetes Federation, 2017. Available at: http://www.diabetesatlas.org (Accessed Oct 29, 2019)

3. Zhang P, Zhang X, Brown J, Vistisen D, Sicree R, Shaw J, Nichols G. Global healthcare expenditure on diabetes for 2010 and 2030. Diabetes Res Clin Pract (2010) 87:293-301. doi:10.1016/j.diabres.2010.01.026

4. Chevreul K, Berg Brigham K, Bouché C. The burden and treatment of diabetes in France. Glob Health (2014) 10:6. doi:10.1186/1744-8603-10-6

5. da Rocha Fernandes J, Ogurtsova K, Linnenkamp U, Guariguata L, Seuring T, Zhang P, Cavan D, Makaroff LE. IDF Diabetes Atlas estimates of 2014 global health expenditures on diabetes. Diabetes Res Clin Pract (2016) 117:48-54.

doi:10.1016/j.diabres.2016.04.016

6. Zheng Y, Ley SH, Hu FB. Global aetiology and epidemiology of type 2 diabetes mellitus and its complications. Nat Rev Endocrinol (2018) 14:88-98. doi:10.1038/nrendo.2017.151

7. Sami W, Ansari T, Butt NS, Hamid MRA. Effect of diet on type 2 diabetes mellitus: A review. Int J Health Sci (2017) 11:65-71.

8. World Health Organization. 2008-2013 Action Plan for the Global Strategy for the Prevention and Control of Noncommunicable Diseases. Geneva (2008).

9. Steinbrecher A, Morimoto Y, Heak S, Ollberding NJ, Geller KS, Grandinetti A, Kolonel LN, Maskarinec G. The preventable proportion of type 2 diabetes by ethnicity: the multiethnic cohort. Ann Epidemiol (2011) 21:526-535.

doi:10.1016/j.annepidem.2011.03.009

10. Jannasch F, Kröger J, Schulze MB. Dietary Patterns and Type 2 Diabetes: A Systematic Literature Review and Meta-Analysis of Prospective Studies. J Nutr (2017) 147:11741182. doi:10.3945/jn.116.242552

11. Qian F, Liu G, Hu FB, Bhupathiraju SN, Sun Q. Association Between Plant-Based Dietary Patterns and Risk of Type 2 Diabetes: A Systematic Review and Meta-analysis. JAMA Intern Med (2019) doi:10.1001/jamainternmed.2019.2195

12. Schwingshackl L, Hoffmann G, Lampousi A-M, Knüppel S, Iqbal K, Schwedhelm C, Bechthold A, Schlesinger S, Boeing H. Food groups and risk of type 2 diabetes mellitus: a systematic review and meta-analysis of prospective studies. Eur J Epidemiol (2017) 32:363-375. doi:10.1007/s10654-017-0246-y

13. Olfert MD, Wattick RA. Vegetarian Diets and the Risk of Diabetes. Curr Diab Rep (2018) 18:101. doi:10.1007/s11892-018-1070-9 
14. Schwingshackl L, Missbach B, König J, Hoffmann G. Adherence to a Mediterranean diet and risk of diabetes: a systematic review and meta-analysis. Public Health Nutr (2015) 18:1292-1299. doi:10.1017/S1368980014001542

15. Lee Y, Park K. Adherence to a Vegetarian Diet and Diabetes Risk: A Systematic Review and Meta-Analysis of Observational Studies. Nutrients (2017) 9: doi:10.3390/nu9060603

16. U.S. Department of Health and Human Services and U.S. Department of Agriculture. 2015 - 2020 Dietary Guidelines for Americans. (2015)

17. Rhodes DG, Adler ME, Clemens JC, LaComb RP, Moshfegh AJ. Consumption of Pizza: What We Eat in America, NHANES 2007-2010. Food Surveys Research Group Dietary Data Brief No. 11. (2014)

18. Dubuisson C, Lioret S, Touvier M, Dufour A, Calamassi-Tran G, Volatier J-L, Lafay L. Trends in food and nutritional intakes of French adults from 1999 to 2007: results from the INCA surveys. Br J Nutr (2010) 103:1035-1048. doi:10.1017/S0007114509992625

19. Agence française de sécurité sanitaire des aliments (AFSSA). Etude Individuelle Nationale des Consommations Alimentaires 2 (INCA2) 2006-2007 [Individual National Study of Food Consumption 2006-2007]. Maison-Alfort: AFSSA (2009).

20. Hagstromer M, Oja P, Sjostrom M. The International Physical Activity Questionnaire (IPAQ): a study of concurrent and construct validity. Public Health Nutr (2006) 9:755762.

21. Le Moullec N, Deheeger M, Preziosi P, et al. Validation du manuel photos utilisé pour l'enquête alimentaire de l'étude SU.VI.MAX [Validation of the photo manual used for the dietary assessment of the SU.VI.MAX study]. Cah Nutr Diet (1996) 31:158-164.

22. Schwingshackl L, Schwedhelm C, Hoffmann G, Boeing H. Potatoes and risk of chronic disease: a systematic review and dose-response meta-analysis. Eur J Nutr (2019) 58:2243-2251. doi:10.1007/s00394-018-1774-2

23. Pimpin L, Wu JHY, Haskelberg H, Del Gobbo L, Mozaffarian D. Is Butter Back? A Systematic Review and Meta-Analysis of Butter Consumption and Risk of Cardiovascular Disease, Diabetes, and Total Mortality. PloS One (2016) 11:e0158118. doi:10.1371/journal.pone.0158118

24. Huang J, Wang X, Zhang Y. Specific types of alcoholic beverage consumption and risk of type 2 diabetes: A systematic review and meta-analysis. J Diabetes Investig (2017) 8:56-68. doi:10.1111/jdi.12537

25. Carlström M, Larsson SC. Coffee consumption and reduced risk of developing type 2 diabetes: a systematic review with meta-analysis. Nutr Rev (2018) 76:395-417. doi:10.1093/nutrit/nuy014

26. Yang W-S, Wang W-Y, Fan W-Y, Deng Q, Wang X. Tea consumption and risk of type 2 diabetes: a dose-response meta-analysis of cohort studies. Br J Nutr (2014) 111:13291339. doi:10.1017/S0007114513003887 
27. Yuan S, Li X, Jin Y, Lu J. Chocolate Consumption and Risk of Coronary Heart Disease, Stroke, and Diabetes: A Meta-Analysis of Prospective Studies. Nutrients (2017) 9: doi:10.3390/nu9070688

28. Neuenschwander M, Ballon A, Weber KS, Norat T, Aune D, Schwingshackl L, Schlesinger S. Role of diet in type 2 diabetes incidence: umbrella review of metaanalyses of prospective observational studies. BMJ (2019) 366:12368. doi:10.1136/bmj.l2368

29. Li M, Fan Y, Zhang X, Hou W, Tang Z. Fruit and vegetable intake and risk of type 2 diabetes mellitus: meta-analysis of prospective cohort studies. BMJ Open (2014) 4:e005497. doi:10.1136/bmjopen-2014-005497

30. InterAct Consortium. Dietary fibre and incidence of type 2 diabetes in eight European countries: the EPIC-InterAct Study and a meta-analysis of prospective studies. Diabetologia (2015) 58:1394-1408. doi:10.1007/s00125-015-3585-9

31. Greenwood DC, Threapleton DE, Evans CEL, Cleghorn CL, Nykjaer C, Woodhead C, Burley VJ. Glycemic index, glycemic load, carbohydrates, and type 2 diabetes: systematic review and dose-response meta-analysis of prospective studies. Diabetes Care (2013) 36:4166-4171. doi:10.2337/dc13-0325

32. Dong J-Y, Xun P, He K, Qin L-Q. Magnesium intake and risk of type 2 diabetes: metaanalysis of prospective cohort studies. Diabetes Care (2011) 34:2116-2122. doi:10.2337/dc11-0518

33. Rienks J, Barbaresko J, Oluwagbemigun K, Schmid M, Nöthlings U. Polyphenol exposure and risk of type 2 diabetes: dose-response meta-analyses and systematic review of prospective cohort studies. Am J Clin Nutr (2018) 108:49-61. doi:10.1093/ajcn/nqy083

34. Scarborough P, Morgan RD, Webster P, Rayner M. Differences in coronary heart disease, stroke and cancer mortality rates between England, Wales, Scotland and Northern Ireland: the role of diet and nutrition. BMJ Open (2011) 1:e000263. doi:10.1136/bmjopen-2011-000263

35. Scarborough P, Harrington RA, Mizdrak A, Zhou LM, Doherty A. The Preventable Risk Integrated ModEl and Its Use to Estimate the Health Impact of Public Health Policy Scenarios. Scientifica (2014) 2014:748750. doi:10.1155/2014/748750

36. Kesse-Guyot E, Amieva H, Castetbon K, Henegar A, Ferry M, Jeandel C, Hercberg S, Galan P, SU.VI.MAX 2 Research Group. Adherence to nutritional recommendations and subsequent cognitive performance: findings from the prospective Supplementation with Antioxidant Vitamins and Minerals 2 (SU.VI.MAX 2) study. Am J Clin Nutr (2011) 93:200-210. doi:10.3945/ajcn.2010.29761

37. Estaquio C, Kesse-Guyot E, Deschamps V, Bertrais S, Dauchet L, Galan P, Hercberg S, Castetbon K. Adherence to the French Programme National Nutrition Sante Guideline Score is associated with better nutrient intake and nutritional status. JAmDietAssoc (2009) 109:1031-1041. 
38. Sofi F, Macchi C, Abbate R, Gensini GF, Casini A. Mediterranean diet and health status: an updated meta-analysis and a proposal for a literature-based adherence score. Public Health Nutr (2014) 17:2769-2782.

39. Martínez-González MA, Sánchez-Tainta A, Corella D, Salas-Salvadó J, Ros E, Arós F, Gómez-Gracia E, Fiol M, Lamuela-Raventós RM, Schröder H, et al. A provegetarian food pattern and reduction in total mortality in the Prevención con Dieta Mediterránea (PREDIMED) study. Am J Clin Nutr (2014) 100 Suppl 1:320S-8S. doi:10.3945/ajcn.113.071431

40. Aune D, Norat T, Romundstad P, Vatten LJ. Whole grain and refined grain consumption and the risk of type 2 diabetes: a systematic review and dose-response meta-analysis of cohort studies. Eur J Epidemiol (2013) 28:845-858. doi:10.1007/s10654-013-9852-5

41. Venn BJ, Mann JI. Cereal grains, legumes and diabetes. Eur J Clin Nutr (2004) 58:1443-1461. doi:10.1038/sj.ejcn.1601995

42. Steyn NP, Mann J, Bennett PH, Temple N, Zimmet P, Tuomilehto J, Lindström J, Louheranta A. Diet, nutrition and the prevention of type 2 diabetes. Public Health Nutr (2004) 7:147-165. doi:10.1079/phn2003586

43. Xu Y, Wan Q, Feng J, Du L, Li K, Zhou Y. Whole grain diet reduces systemic inflammation. Medicine (Baltimore) (2018) 97: doi:10.1097/MD.0000000000012995

44. Toplak H, Leitner DR, Harreiter J, Hoppichler F, Wascher TC, Schindler K, Ludvik B. ["Diabesity"-Obesity and type 2 diabetes (Update 2019)]. Wien Klin Wochenschr (2019) 131:71-76. doi:10.1007/s00508-018-1418-9

45. Verger EO, Holmes BA, Huneau JF, Mariotti F. Simple changes within dietary subgroups can rapidly improve the nutrient adequacy of the diet of French adults. $J$ Nutr (2014) 144:929-936. doi:10.3945/jn.113.188284

46. Fuentes S, Mandereau-Bruno L, Regnault N, Bernillon P, Bonaldi C, Cosson E, FosseEdorh S. Is the type 2 diabetes epidemic plateauing in France? A nationwide populationbased study. Diabetes Metab (2020) 46:472-479. doi:10.1016/j.diabet.2019.12.006 
Table 1 Characteristics of the study population, INCA2 study †

\begin{tabular}{|c|c|c|c|c|c|}
\hline \multirow[t]{2}{*}{ Characteristics } & \multicolumn{2}{|c|}{$\begin{array}{c}\text { Pizza consumers } \\
(n=\mathbf{8 8 0})\end{array}$} & \multicolumn{2}{|c|}{$\begin{array}{c}\text { Non pizza consumers } \\
(n=1,630)\end{array}$} & \multirow[t]{2}{*}{$\mathbf{P} \ddagger$} \\
\hline & Men & Women & Men & Women & \\
\hline$n$ & 426 & 454 & 650 & 980 & \\
\hline Age, years & $41.2 \pm 14.3$ & $39.2 \pm 14.3$ & $50.1 \pm 15.2$ & $48.0 \pm 14.9$ & $<0.0001$ \\
\hline Marital status, $n$ (\%) & & & & & $<0.0001$ \\
\hline Living alone & $103(24.2)$ & $110(24.2)$ & $121(18.6)$ & $147(15.0)$ & \\
\hline Married/Cohabiting & $286(67.1)$ & $275(60.6)$ & $456(70.2)$ & $606(61.8)$ & \\
\hline Divorced/Widowed & $37(8.7)$ & $69(15.2)$ & $73(11.2)$ & $225(23.0)$ & \\
\hline Missing values & 0 & 0 & 0 & $2(0.2)$ & \\
\hline Educational level, $n$ (\%) & & & & & 0.0002 \\
\hline$<$ High school diploma & $210(49.3)$ & $200(44.0)$ & $356(54.8)$ & $517(52.8)$ & \\
\hline High school diploma & $84(19.7)$ & $97(21.4)$ & $86(13.2)$ & $167(17.0)$ & \\
\hline University level & $132(31.0)$ & $156(34.4)$ & 207 (31.9) & $295(30.1)$ & \\
\hline Missing values & 0 & $1(0.2)$ & $1(0.1)$ & $1(0.1)$ & \\
\hline Employment status, $n$ (\%) & & & & & $<0.0001$ \\
\hline Employed/Self-employed & 304 (71.4) & 269 (59.3) & 383 (58.9) & $535(54.6)$ & \\
\hline Unemployed & $33(7.7)$ & $90(19.8)$ & $43(6.6)$ & 205 (20.9) & \\
\hline Students & 38 (8.9) & $52(11.4)$ & $21(3.2)$ & $29(3.0)$ & \\
\hline Retired/Early-retired & $51(12.0)$ & $43(9.5)$ & $203(31.3)$ & $211(21.5)$ & \\
\hline Smoking, n (\%) & & & & & 0.002 \\
\hline Non smokers & $133(31.2)$ & $203(44.7)$ & $190(29.2)$ & 487 (49.7) & \\
\hline Former smokers & $132(31.0)$ & $94(20.7)$ & $247(38.0)$ & $220(22.5)$ & \\
\hline Current smokers & $158(37.1)$ & $146(32.2)$ & $202(31.1)$ & $247(25.2)$ & \\
\hline Missing values & $3(0.7)$ & $11(2.4)$ & $11(1.7)$ & $26(2.6)$ & \\
\hline Body mass index, $n(\%)$ & & & & & 0.0002 \\
\hline Underweight/Normal weight & $243(57.0)$ & $321(70.7)$ & $290(44.6)$ & $608(62.0)$ & \\
\hline Overweight & $132(31.0)$ & $88(19.4)$ & $282(43.4)$ & $228(23.3)$ & \\
\hline Obesity & $51(12.0)$ & $43(9.5)$ & $75(11.5)$ & $127(13.0)$ & \\
\hline Missing values & 0 & $2(0.4)$ & $3(0.5)$ & $17(1.7)$ & \\
\hline Number of recording days & $6.9 \pm 0.4$ & $6.9 \pm 0.4$ & $6.9 \pm 0.6$ & $6.9 \pm 0.5$ & 0.02 \\
\hline Total energy intake, Kcal/days & $2347 \pm 613$ & $1830 \pm 452$ & $2382 \pm 677$ & $1834 \pm 466$ & 0.27 \\
\hline Energy intake without alcohol, Kcal/d & $2213 \pm 582$ & $1787 \pm 438$ & $2223 \pm 640$ & $1784 \pm 452$ & 0.15 \\
\hline Carbohydrates, \% energy $\S$ & $44.6 \pm 5.8$ & $43.5 \pm 5.9$ & $43.5 \pm 6.6$ & $42.9 \pm 5.9$ & 0.0003 \\
\hline Plant proteins, \% energy § & $4.9 \pm 0.8$ & $4.6 \pm 0.8$ & $4.9 \pm 1.0$ & $4.6 \pm 0.9$ & 0.25 \\
\hline Animal proteins, \% energy $\S$ & $11.7 \pm 2.8$ & $11.2 \pm 2.9$ & $12.3 \pm 3.4$ & $11.8 \pm 3.2$ & $<0.0001$ \\
\hline Lipids, \% energy $\S$ & $37.6 \pm 5.2$ & $38.9 \pm 5.5$ & $38.0 \pm 6.1$ & $38.6 \pm 5.7$ & 0.81 \\
\hline Fruit and vegetables consumption, $n(\%)$ & & & & & $<0.0001$ \\
\hline$<400$ g/days & $337(79.1)$ & $355(78.2)$ & $434(66.8)$ & $638(65.1)$ & \\
\hline$\geq 400 \mathrm{~g} /$ days & 89 (20.9) & $99(21.8)$ & $216(33.2)$ & 342 (34.9) & \\
\hline \multicolumn{6}{|l|}{ Diet quality scores } \\
\hline mPNNS-GS \| & $7.9 \pm 1.4$ & $8.2 \pm 1.4$ & $8.0 \pm 1.5$ & $8.4 \pm 1.5$ & 0.001 \\
\hline MEDI-LITE & $7.2 \pm 2.4$ & $7.2 \pm 2.4$ & $7.7 \pm 2.7$ & $7.7 \pm 2.6$ & $<0.0001$ \\
\hline Provegetarian FP & $35.7 \pm 4.8$ & $35.6 \pm 4.8$ & $36.1 \pm 5.1$ & $35.9 \pm 5.0$ & 0.11 \\
\hline \multicolumn{6}{|l|}{ Pizza consumption, $\mathbf{n}(\%)$ ף } \\
\hline 1 & $316(74.2)$ & $372(82.0)$ & & & \\
\hline 2 & $74(17.4)$ & $66(14.5)$ & & & \\
\hline$\geq 3$ & $36(8.4)$ & $16(3.5)$ & & & \\
\hline Average pizza portion size, $\mathrm{g}$ & $262.0 \pm 153.9$ & $187.3 \pm 132.0$ & & & \\
\hline
\end{tabular}

INCA2 second Individual and National Food consumption survey; MEDI-LITE Literature-based adherence score to the Mediterranean diet; mPNNS-GS modified Programme National Nutrition Santé Guideline Score; Provegetarian FP Provegetarian food pattern

$\dagger$ Values are means \pm standard deviation or numbers (percentages) as appropriate

$\ddagger \mathrm{P}$-values are based on the T-test or chi-square test, and refer to the comparison between consumers and non-consumers of pizza

$\S$ Values are percentages of total daily energy intake without alcohol

|| 12 missing data among pizza consumers and 35 among non-pizza consumers

I Number of times during the food data collection period 
Table 2 Rates of change in risk of type 2 diabetes (percentage) for substitutions with the best and worst pizzas $\dagger$

\begin{tabular}{|c|c|c|c|c|}
\hline \multirow[t]{2}{*}{ Population } & \multicolumn{2}{|c|}{ Isoenergetic substitution } & \multicolumn{2}{|c|}{ Non-Isoenergetic substitution } \\
\hline & Men & Women & Men & Women \\
\hline \multicolumn{5}{|c|}{$1^{\text {st }}$ Best pizza (\#88) } \\
\hline Whole population & $-2.6(-3.3 ;-1.9)$ & $-1.4(-1.7 ;-1.0)$ & $-3.6(-4.5 ;-2.6)$ & $-2.0(-2.5 ;-1.3)$ \\
\hline Pizza consumers & $-6.7(-8.4 ;-4.9)$ & $-4.5(-5.6 ;-3.3)$ & $-8.9(-11.2 ;-6.3)$ & $-6.0(-7.9 ;-3.9)$ \\
\hline Participants who consumed pizza once & $-5.1(-6.4 ;-3.8)$ & $-3.9(-4.9 ;-2.8)$ & $-6.8(-8.6 ;-4.91)$ & $-5.3(-6.8 ;-3.5)$ \\
\hline Participants who consumed pizza twice & $-9.9(-12.4 ;-7.3)$ & $-6.4(-8.0 ;-4.7)$ & $-12.7(-16.1 ;-8.9)$ & $-7.8(-10.7 ;-4.6)$ \\
\hline Participants who consumed pizza more than twice & $-13.9(-17.2 ;-10.4)$ & $-10.3(-12.8 ;-7.6)$ & $-18.3(-23.2 ;-12.6)$ & $-14.6(-18.5 ;-9.7)$ \\
\hline \multicolumn{5}{|c|}{$2^{\text {nd }}$ Best pizza (\#100) } \\
\hline Whole population & $-2.3(-3.4 ;-1.1)$ & $-1.2(-1.8 ;-0.6)$ & $-2.3(-3.4 ;-1.1)$ & $-1.2(-1.8 ;-0.6)$ \\
\hline Pizza consumers & $-5.7(-8.5 ;-2.8)$ & $-3.8(-5.6 ;-1.9)$ & $-5.7(-8.5 ;-2.8)$ & $-3.7(-5.6 ;-1.8)$ \\
\hline Participants who consumed pizza once & $-4.4(-6.5 ;-2.2)$ & $-3.3(-4.9 ;-1.6)$ & $-4.4(-6.5 ;-2.1)$ & $-3.2(-4.8 ;-1.5)$ \\
\hline Participants who consumed pizza twice & $-8.4(-12.3 ;-4.2)$ & $-5.5(-8.1 ;-2.8)$ & $-8.4(-12.3 ;-4.2)$ & $-5.4(-8.1 ;-2.7)$ \\
\hline Participants who consumed pizza more than twice & $-11.9(-17.4 ;-5.8)$ & $-8.7(-12.9 ;-4.2)$ & $-12.3(-17.8 ;-6.2)$ & $-8.9(-13.1 ;-4.5)$ \\
\hline \multicolumn{5}{|c|}{$1^{\text {st }}$ Worst pizza (\#78) } \\
\hline Whole population & $2.6(1.8 ; 3.4)$ & $1.3(0.9 ; 1.7)$ & $3.9(2.7 ; 5.0)$ & $2.1(1.2 ; 2.8)$ \\
\hline Pizza consumers & $6.6(4.5 ; 8.6)$ & $4.2(2.9 ; 5.4)$ & $9.7(6.5 ; 12.8)$ & $6.5(3.7 ; 8.9)$ \\
\hline Participants who consumed pizza once & $4.8(3.3 ; 6.2)$ & $3.5(2.5 ; 4.6)$ & $7.2(4.8 ; 9.4)$ & $5.6(3.3 ; 7.6)$ \\
\hline Participants who consumed pizza twice & $9.8(6.8 ; 12.8)$ & $6.0(4.2 ; 7.8)$ & $14.4(9.5 ; 19.2)$ & $8.3(4.0 ; 12.4)$ \\
\hline Participants who consumed pizza more than twice & $16.0(10.7 ; 21.4)$ & $10.8(7.5 ; 14.2)$ & $23.0(15.0 ; 30.9)$ & $17.2(10.7 ; 23.0)$ \\
\hline \multicolumn{5}{|c|}{$2^{\text {nd }}$ Worst pizza (\#84) } \\
\hline Whole population & $2.3(1.5 ; 3.0)$ & $1.2(0.8 ; 1.6)$ & $5.2(2.9 ; 7.0)$ & $2.8(1.2 ; 4.2)$ \\
\hline Pizza consumers & $5.6(3.8 ; 7.5)$ & $3.7(2.6 ; 4.9)$ & $13.1(7.1 ; 18.3)$ & $9.0(3.5 ; 13.5)$ \\
\hline Participants who consumed pizza once & $4.1(2.8 ; 5.4)$ & $3.2(2.2 ; 4.1)$ & $9.6(5.2 ; 13.4)$ & $7.8(3.2 ; 11.6)$ \\
\hline Participants who consumed pizza twice & $8.4(5.5 ; 11.2)$ & $5.3(3.6 ; 6.9)$ & $19.6(10.8 ; 27.8)$ & $10.7(2.1 ; 18.7)$ \\
\hline Participants who consumed pizza more than twice & $14.0(9.1 ; 19.0)$ & $9.7(6.6 ; 12.9)$ & $32.4(17.9 ; 46.1)$ & $25.7(12.3 ; 36.9)$ \\
\hline
\end{tabular}




\section{Tailored substitutions}
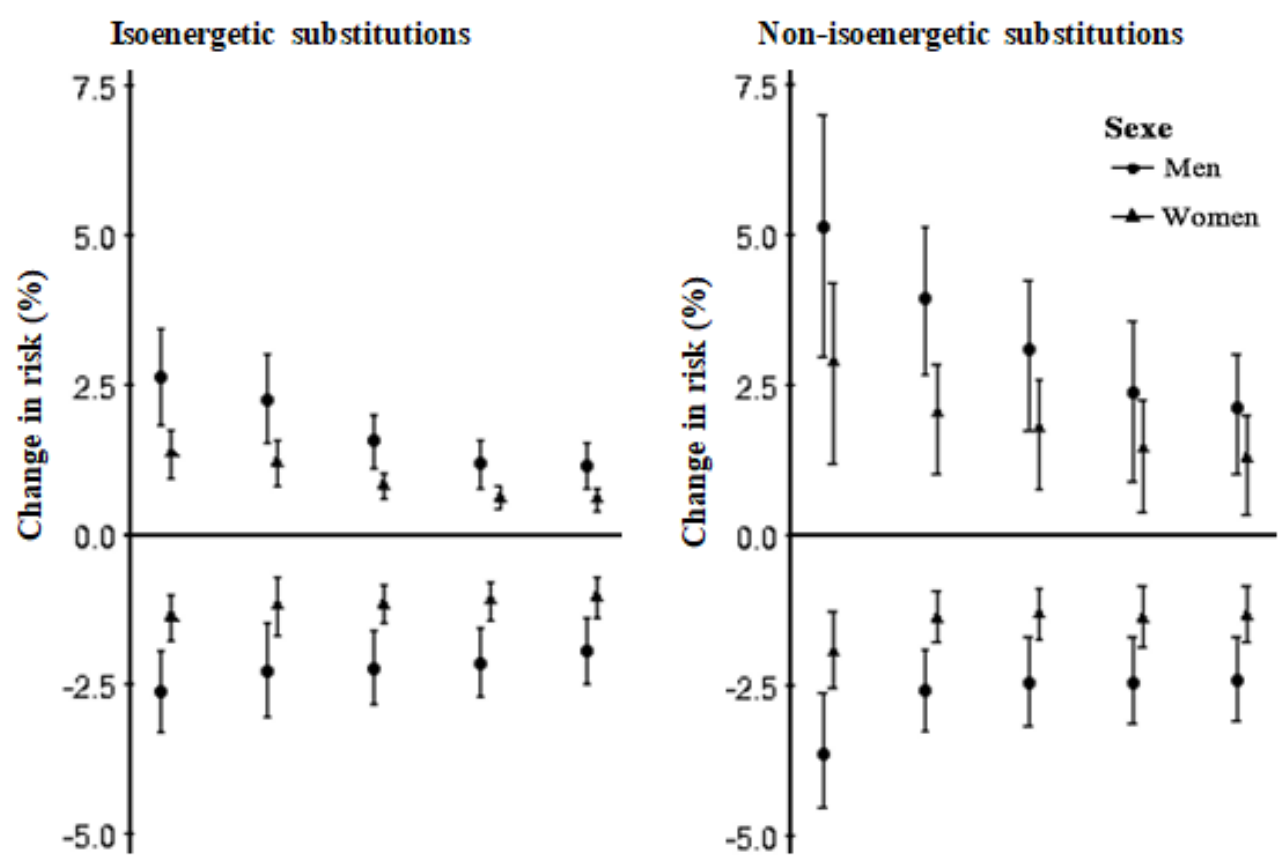

\section{Generic substitutions}
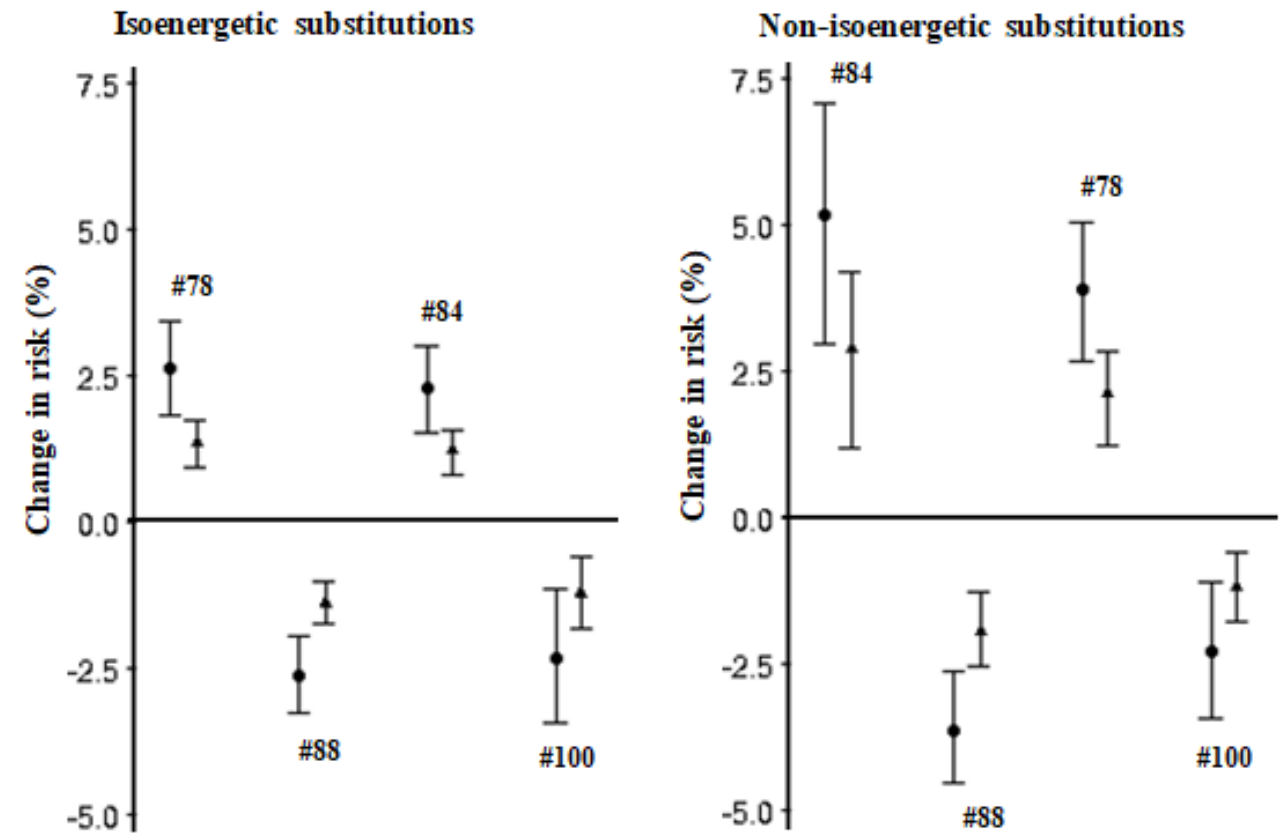

Figure 1. Rates of change in risk of type 2 diabetes in the overall sample population when simulating substitutions with the five best and five worst pizzas (out of 100) specific to each of 2,510 individuals (“tailored substitution”). Upper panels: according to isoenergetic substitutions (upper left) or nonisoenergetic substitutions (upper right); and substitutions with the four pizzas most frequently identified as the best/worst ("generic substitution”), according to isoenergetic substitutions (lower left) or non-isoenergetic substitutions (lower right). The numbers below the estimates are the ID of the pizza. "Pizza" here stands for a cluster of pizzas ( $n=100$, out of 353 pizzas). 
Isoen ergetic substitutions

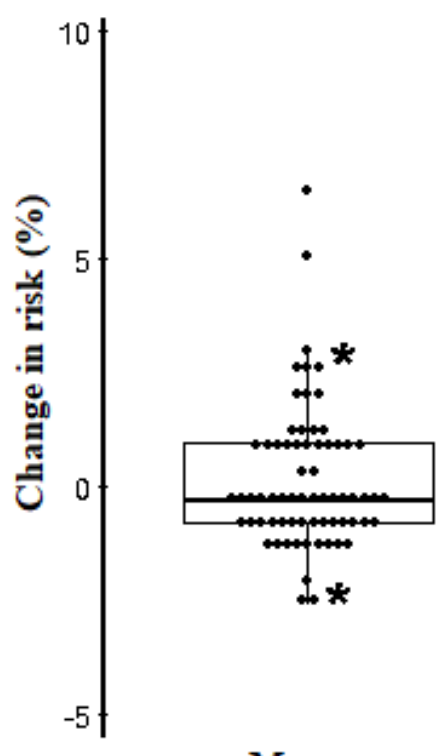

Men
Women

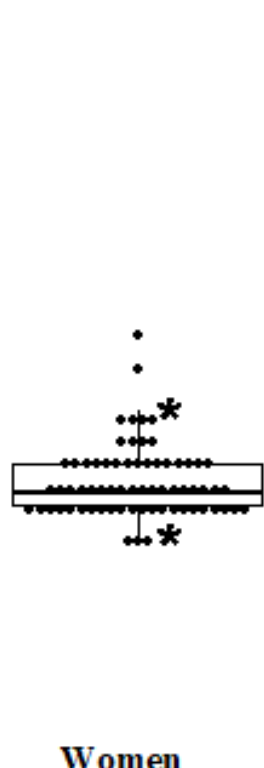

Non-isoen ergetic substitutions
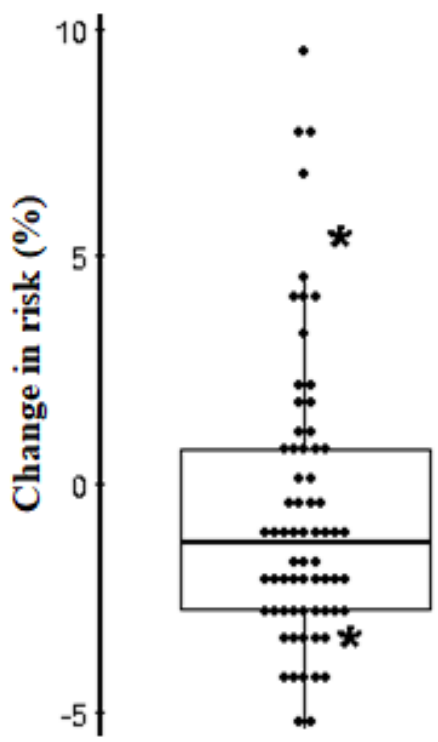

Men

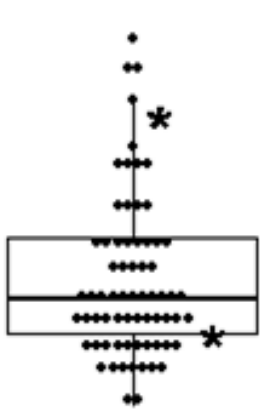

Women

Figure 2. Rates of change in risk of type 2 diabetes in the overall sample when simulating substitutions in each pizza consumer with the mixed dishes $(n=68)$ * reports the estimates found for generic substitutions with the best and worst pizzas (see Figure 1), for the comparison purposes. "Pizza” here stands for a cluster of pizzas ( $n=100$, out of 353 pizzas). 


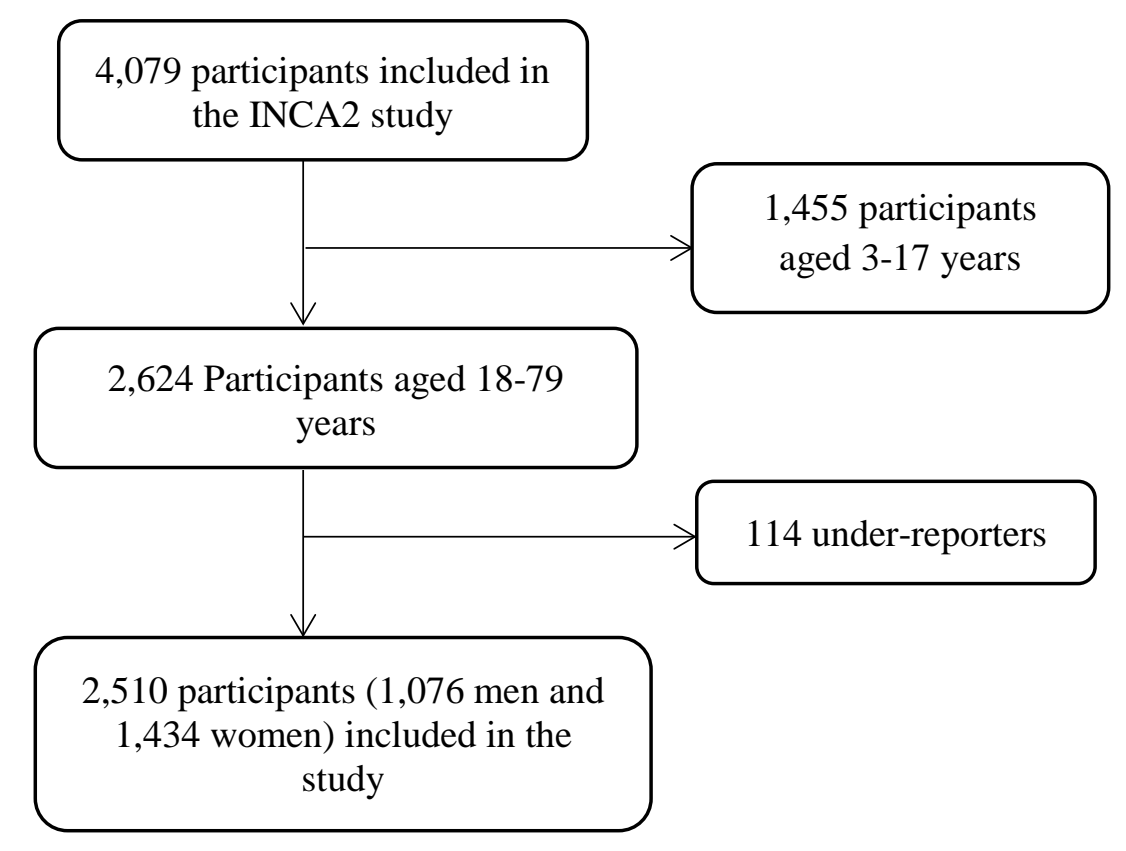

Supplemental Figure 1 Flow chart of participant selection 


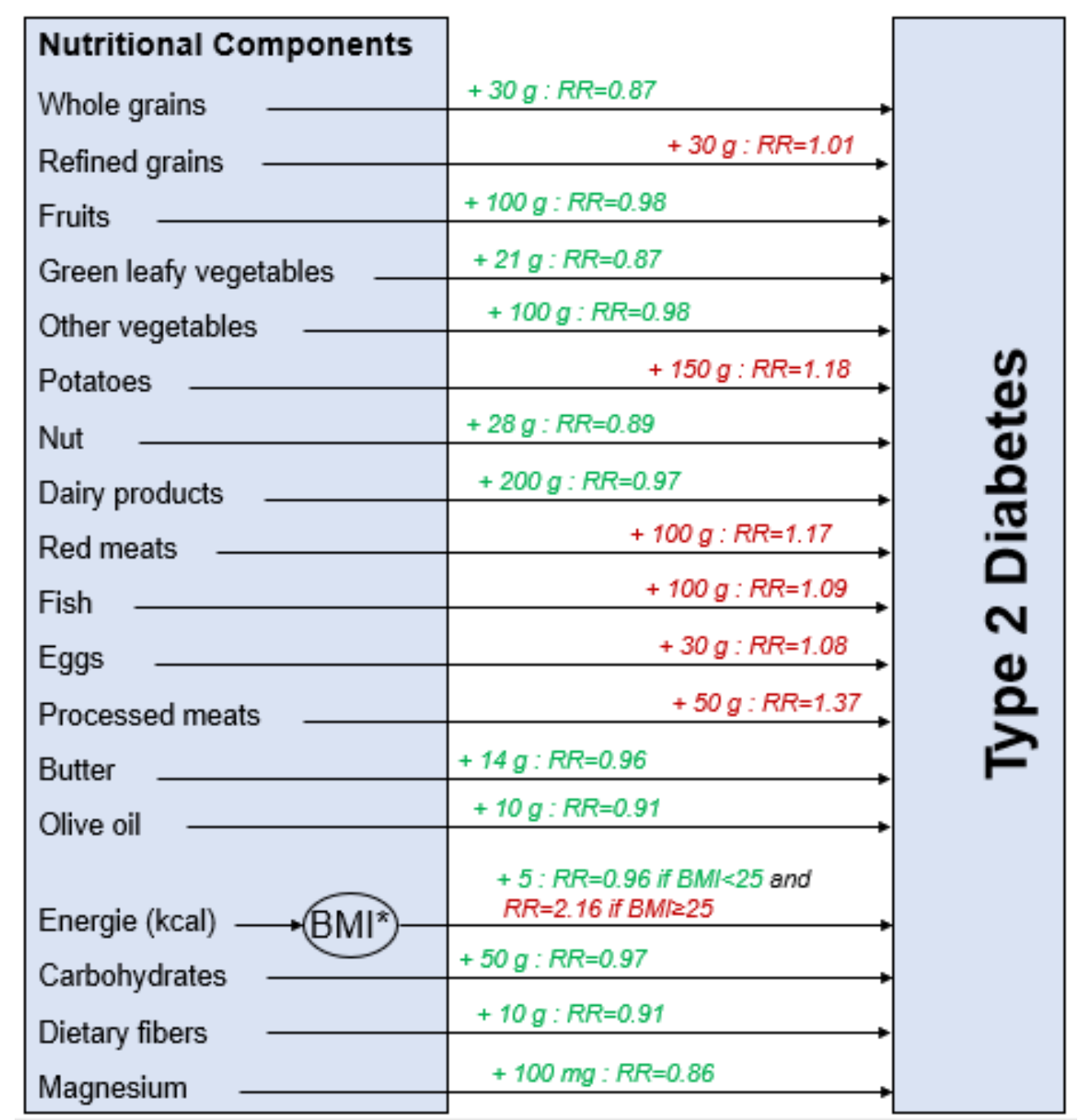

Supplemental Figure 2 Structure and parameters of the macrosimulation model

*The change in BMI was calculated as indicated by Scarborough et al., but at constant physical activity.

\section{References}

Scarborough P, Harrington RA, Mizdrak A, Zhou LM, Doherty A. The Preventable Risk Integrated ModEl and Its Use to Estimate the Health Impact of Public Health Policy Scenarios. Scientifica (2014) 2014:748750. doi:10.1155/2014/748750

Schwingshackl L, Hoffmann G, Lampousi A-M, Knüppel S, Iqbal K, Schwedhelm C, Bechthold A, Schlesinger S, Boeing H. Food groups and risk of type 2 diabetes mellitus: a systematic review and meta-analysis of prospective studies. Eur J Epidemiol (2017) 32:363375. doi:10.1007/s10654-017-0246-y 
Schwingshackl L, Schwedhelm C, Hoffmann G, Boeing H. Potatoes and risk of chronic disease: a systematic review and dose-response meta-analysis. Eur J Nutr (2019) 58:22432251. doi:10.1007/s00394-018-1774-2

Pimpin L, Wu JHY, Haskelberg H, Del Gobbo L, Mozaffarian D. Is Butter Back? A Systematic Review and Meta-Analysis of Butter Consumption and Risk of Cardiovascular Disease, Diabetes, and Total Mortality. PloS One (2016) 11:e0158118.

doi:10.1371/journal.pone.0158118

Li M, Fan Y, Zhang X, Hou W, Tang Z. Fruit and vegetable intake and risk of type 2 diabetes mellitus: meta-analysis of prospective cohort studies. BMJ Open (2014) 4:e005497. doi:10.1136/bmjopen-2014-005497

InterAct Consortium. Dietary fibre and incidence of type 2 diabetes in eight European countries: the EPIC-InterAct Study and a meta-analysis of prospective studies. Diabetologia (2015) 58:1394-1408. doi:10.1007/s00125-015-3585-9

Greenwood DC, Threapleton DE, Evans CEL, Cleghorn CL, Nykjaer C, Woodhead C, Burley VJ. Glycemic index, glycemic load, carbohydrates, and type 2 diabetes: systematic review and dose-response meta-analysis of prospective studies. Diabetes Care (2013) 36:4166-4171. doi:10.2337/dc13-0325

Dong J-Y, Xun P, He K, Qin L-Q. Magnesium intake and risk of type 2 diabetes: metaanalysis of prospective cohort studies. Diabetes Care (2011) 34:2116-2122.

doi:10.2337/dc11-0518 
mPNNS-GS (Kesse-Guyot et al., 2011a ; Estaquio C. et al, 2009) †

\begin{tabular}{|c|c|c|}
\hline Food intake recommendations & Moderation in consumption & Penalty \\
\hline $\begin{array}{c}\text { Fruit and vegetables without potatoes (0-2), starchy foods } \\
(0-1), \text { whole grain products }(0-1) \text {, milk and dairy products } \\
(0-1), \text { meat, poultry, fish, eggs, and seafood (0-1), seafood } \\
(0-1) \text {, vegetable fat }(0-1) \text {, water vs soda }(0-1)\end{array}$ & $\begin{array}{c}\text { Sweetened foods (-0.5-1), salt } \\
(-0.5-1.5) \text {, added fats }(0-2),\end{array}$ & $\begin{array}{c}\text { Deduction of points } \\
\text { if energy intake } \\
\text { exceeded energy } \\
\text { needs by } 5 \%\end{array}$ \\
\hline \multicolumn{2}{|c|}{ The mPNNS-GS score is the sum of components minus penalty (range: $\mathbf{0 - 1 3 . 5}$ points) } \\
\hline
\end{tabular}

MEDI-LITE (Sofi F. et al, 2013)

\begin{tabular}{|c|c|}
\hline $\begin{array}{c}\text { Desirable components (0-2 points for each } \\
\text { component) }\end{array}$ & $\begin{array}{c}\text { Undesirable components (0-2 points for each } \\
\text { component) }\end{array}$ \\
\hline $\begin{array}{c}\text { Fruit, vegetables without potatoes, grains, legumes, } \\
\text { fish, olive oil, moderate alcohol consumption }\end{array}$ & Meat/meat products, dairy products \\
\hline \multicolumn{2}{|c|}{ The MEDI-LITE score is the sum of components (range: 0-18 points) } \\
\hline \multicolumn{2}{|c|}{. }
\end{tabular}

Provegetarian food pattern (Martínez-González. et al, 2014) §

\begin{tabular}{|c|c|}
\hline $\begin{array}{l}\text { Vegetable food groups (1-5 points for each food } \\
\text { group) }\end{array}$ & $\begin{array}{l}\text { Animal food groups (1-5 points for each food } \\
\text { group) }\end{array}$ \\
\hline Fruit, vegetables, legumes, cereals, potatoes, nuts, olive oil & $\begin{array}{l}\text { Meats/meat products, eggs, animal fats for cooking or as } \\
\text { a spread, Fish and other seafood, dairy products }\end{array}$ \\
\hline \multicolumn{2}{|c|}{ The Provegetarian FP is the sum of the sex-specific quintile values of the 12 food groups (range: $12-60$ points) } \\
\hline \multirow{2}{*}{\multicolumn{2}{|c|}{$\begin{array}{l}\text { MEDI-LITE Literature-Based Adherence Score to the Mediterranean Diet; mPNNS-GS modified Programme National Nutrition Santé Guideline Score } \\
\text { † Values were assigned by using fixed portion numbers for each food group, with a maximum of points attributed for high consumption of "desirable" } \\
\text { components }\end{array}$}} \\
\hline & \\
\hline \multicolumn{2}{|c|}{$\begin{array}{l}\text { † Values were assigned to food groups by using fixed cut-off points (portion sizes multiplied by the number of servings per day/week) determined from } \\
\text { an extensive published review of the literature. A maximum of points is attributed for high consumption of "desirable” components and the scoring was } \\
\text { reversed for the "undesirable” components. }\end{array}$} \\
\hline
\end{tabular}

Supplemental Figure 3 Computation of diet quality scores 
Supplemental table 1 Nutritional characteristics of the 100 pizza clusters

\begin{tabular}{|c|c|c|c|c|c|c|c|c|c|c|c|c|c|c|c|}
\hline \multirow[t]{2}{*}{ Cluster } & \multirow{2}{*}{$\begin{array}{l}\text { Number } \\
\text { of pizzas }\end{array}$} & \multicolumn{10}{|c|}{ Average composition per $100 \mathrm{~g}$} & \multicolumn{2}{|c|}{$\begin{array}{c}\text { Isoenergetic } \\
\text { substitution } \dagger\end{array}$} & \multicolumn{2}{|c|}{$\begin{array}{c}\text { Non-Isoenergetic } \\
\text { substitution } \ddagger\end{array}$} \\
\hline & & $\begin{array}{l}\text { Energy } \\
\text { (Kcal) }\end{array}$ & $\begin{array}{l}\text { Whole } \\
\text { grains (g) }\end{array}$ & $\begin{array}{l}\text { Refined } \\
\text { grains (g) }\end{array}$ & $\begin{array}{l}\text { Dairy } \\
\text { products (g) }\end{array}$ & $\begin{array}{l}\text { Green leafy } \\
\text { vegetables (g) }\end{array}$ & $\begin{array}{l}\text { Other } \\
\text { vegetables (g) }\end{array}$ & $\begin{array}{l}\text { Fish } \\
\text { (g) }\end{array}$ & $\begin{array}{l}\text { Red } \\
\text { meat (g) }\end{array}$ & $\begin{array}{l}\text { Processed } \\
\text { meat (g) }\end{array}$ & $\begin{array}{l}\text { Olive } \\
\text { oil (g) }\end{array}$ & $\begin{array}{l}1^{\text {st }} \text { best or } \\
\text { worst }(n)\end{array}$ & $\begin{array}{l}2^{\text {nd }} \text { best or } \\
\text { worst }(n)\end{array}$ & $\begin{array}{l}1^{\text {st }} \text { best or } \\
\text { worst }(n)\end{array}$ & $\begin{array}{l}2^{\text {nd }} \text { best or } \\
\text { worst }(n)\end{array}$ \\
\hline$\# \mathbf{1}$ & 4 & $200.6 \pm 6.5$ & 0 & $28.5 \pm 0.3$ & $12.7 \pm 4.1$ & 0 & $4.6 \pm 1.9$ & 0 & 0 & $11.6 \pm 1.5$ & 0 & & & & \\
\hline \#2 & 6 & $200.5 \pm 7.7$ & 0 & $30.0 \pm 0.7$ & $10.7 \pm 3.5$ & 0 & $19.5 \pm 3.0$ & 0 & 0 & $12.8 \pm 0.7$ & 0 & & & & \\
\hline \#3 & 14 & $241.9 \pm 11.6$ & 0 & $29.8 \pm 1.1$ & $24.7 \pm 2.2$ & 0 & $23.0 \pm 2.2$ & 0 & 0 & 0 & 0 & & & & \\
\hline \#4 & 8 & $229.9 \pm 12.0$ & 0 & $28.1 \pm 0.6$ & $13.5 \pm 2.5$ & 0 & $24.2 \pm 2.3$ & 0 & 0 & $13.2 \pm 0.5$ & 0 & & & & \\
\hline \#5 & 4 & $186.8 \pm 2.9$ & 0 & $27.8 \pm 0.6$ & $8.5 \pm 0.7$ & 0 & $32.1 \pm 2.5$ & 0 & 0 & $8.9 \pm 0.2$ & 0 & & & & \\
\hline$\# 6$ & 7 & $243.4 \pm 9.7$ & 0 & $27.1 \pm 0.9$ & $19.7 \pm 2.3$ & 0 & $22.7 \pm 2.0$ & 0 & 0 & $9.8 \pm 0.8$ & 0 & & & & \\
\hline \#7 & 7 & $208.6 \pm 6.3$ & 0 & $27.6 \pm 1.3$ & $18.8 \pm 1.9$ & 0 & $33.1 \pm 2.5$ & 0 & 0 & 0 & 0 & & & & \\
\hline$\# 8$ & 2 & $219.3 \pm 1.0$ & 0 & $36.7 \pm 0.0$ & $4.5 \pm 0.0$ & 0 & $17.4 \pm 0.0$ & 0 & 0 & $14.8 \pm 0.0$ & 0 & & & & \\
\hline$\# \mathbf{9}$ & 9 & $213.9 \pm 10.6$ & 0 & $23.1 \pm 0.8$ & $16.2 \pm 1.4$ & 0 & $29.4 \pm 3.0$ & 0 & 0 & $12.3 \pm 1.6$ & 0 & & & & \\
\hline \#10 & 12 & $202.3 \pm 7.4$ & 0 & $24.3 \pm 1.3$ & $16.0 \pm 1.8$ & 0 & $21.5 \pm 1.4$ & 0 & 0 & $18.1 \pm 2.3$ & 0 & & $2 \mathrm{w}$ & & \\
\hline$\# 11$ & 5 & $258.0 \pm 13.4$ & 0 & $25.0 \pm 0.9$ & $18.4 \pm 0.9$ & 0 & $19.5 \pm 2.2$ & 0 & 0 & $16.5 \pm 1.0$ & 0 & & & & \\
\hline$\# 12$ & 13 & $198.8 \pm 7.7$ & 0 & $25.2 \pm 1.0$ & $12.1 \pm 1.3$ & 0 & $31.3 \pm 2.2$ & 0 & 0 & $11.2 \pm 0.8$ & 0 & & & & \\
\hline$\# 13$ & 8 & $236.4 \pm 12.1$ & 0 & $22.4 \pm 0.6$ & $36.4 \pm 2.7$ & 0 & $23.0 \pm 4.8$ & 0 & 0 & 0 & 0 & & & & \\
\hline$\# 14$ & 13 & $257.6 \pm 10.8$ & 0 & $25.7 \pm 0.8$ & $31.6 \pm 2.0$ & 0 & $23.6 \pm 3.0$ & 0 & 0 & 0 & 0 & & & & \\
\hline$\# 15$ & 6 & $209.7 \pm 5.0$ & 0 & $25.8 \pm 0.9$ & $11.0 \pm 4.1$ & 0 & $31.1 \pm 2.7$ & 0 & 0 & $6.9 \pm 1.1$ & 0 & & & & \\
\hline$\# 16$ & 6 & $230.5 \pm 8.3$ & 0 & $32.2 \pm 2.6$ & $10.6 \pm 2.9$ & 0 & $22.1 \pm 3.1$ & 0 & 0 & $9.5 \pm 0.9$ & 0 & & & & \\
\hline$\# 17$ & 10 & $193.3 \pm 5.5$ & 0 & $27.0 \pm 0.7$ & $16.8 \pm 2.1$ & 0 & $26.3 \pm 1.5$ & 0 & 0 & $9.2 \pm 1.9$ & 0 & & & & \\
\hline \#18 & 4 & $186.5 \pm 5.4$ & 0 & $25.4 \pm 0.8$ & $4.0 \pm 3.3$ & 0 & $40.9 \pm 2.5$ & 0 & 0 & $2.2 \pm 4.5$ & 0 & & & & \\
\hline \#19 & 12 & $224.4 \pm 6.4$ & 0 & $27.7 \pm 1.2$ & $28.6 \pm 3.2$ & $0.04 \pm 0.1$ & $20.4 \pm 3.2$ & 0 & 0 & $0.6 \pm 2.0$ & 0 & & & & \\
\hline$\# 20$ & 6 & $269.2 \pm 8.0$ & 0 & $25.5 \pm 1.3$ & $12.2 \pm 4.4$ & 0 & $26.9 \pm 2.4$ & 0 & 0 & $14.1 \pm 1.0$ & 0 & & & & \\
\hline \#21 & 4 & $227.3 \pm 8.4$ & 0 & $30.8 \pm 1.2$ & $15.2 \pm 1.0$ & 0 & $24.6 \pm 1.7$ & 0 & 0 & $8.2 \pm 1.6$ & 0 & & & & \\
\hline \#22 & 3 & $259.3 \pm 3.1$ & $12.5 \pm 0.2$ & $12.5 \pm 0.2$ & $36.6 \pm 1.6$ & 0 & $19.6 \pm 1.1$ & 0 & 0 & 0 & 0 & $8^{b}$ & $146^{b}$ & & \\
\hline \#23 & 2 & $195.0 \pm 5.7$ & 0 & $32.9 \pm 0.2$ & 0 & 0 & $33.7 \pm 0.3$ & 0 & 0 & 0 & 0 & & & & \\
\hline
\end{tabular}

$\dagger$ Number of participants for whom the cluster was identified as the first or second best (b) / worst (w) pizza for isoenergetic substitutions

$\ddagger$ Number of participants for whom the cluster was identified as the first or second best (b) / worst (w) pizza for non-isoenergetic substitutions 


\begin{tabular}{|c|c|c|c|c|c|c|c|c|c|c|c|c|c|c|c|}
\hline \multirow[t]{2}{*}{ Cluster } & \multirow{2}{*}{$\begin{array}{l}\text { Number } \\
\text { of pizzas }\end{array}$} & \multicolumn{10}{|c|}{ Average composition per $100 \mathrm{~g}$} & \multicolumn{2}{|c|}{$\begin{array}{c}\text { Isoenergetic } \\
\text { substitution } \dagger\end{array}$} & \multicolumn{2}{|c|}{$\begin{array}{c}\text { Non-Isoenergetic } \\
\text { substitution } \ddagger\end{array}$} \\
\hline & & $\begin{array}{l}\text { Energy } \\
\text { (Kcal) }\end{array}$ & $\begin{array}{l}\text { Whole } \\
\text { grains (g) }\end{array}$ & $\begin{array}{l}\text { Refined } \\
\text { grains (g) }\end{array}$ & $\begin{array}{l}\text { Dairy } \\
\text { products } \\
\text { (g) }\end{array}$ & $\begin{array}{l}\text { Green leafy } \\
\text { vegetables } \\
\text { (g) }\end{array}$ & $\begin{array}{l}\text { Other } \\
\text { vegetables } \\
\text { (g) }\end{array}$ & Fish (g) & $\begin{array}{l}\text { Red meat } \\
\text { (g) }\end{array}$ & $\begin{array}{l}\text { Processed } \\
\text { meat (g) }\end{array}$ & $\begin{array}{l}\text { Olive } \\
\text { oil (g) }\end{array}$ & $\begin{array}{l}1^{\text {st }} \text { best or } \\
\text { worst }(n)\end{array}$ & $\begin{array}{l}2^{\text {nd }} \text { best } \\
\text { or worst } \\
(n)\end{array}$ & $\begin{array}{l}1^{\text {st }} \text { best or } \\
\text { worst }(n)\end{array}$ & $\begin{array}{l}2^{\text {nd }} \text { best } \\
\text { or worst } \\
(n)\end{array}$ \\
\hline$\# 24$ & 4 & $258.5 \pm 5.3$ & 0 & $30.0 \pm 0.4$ & $31.4 \pm 1.4$ & 0 & $16.9 \pm 1.7$ & 0 & 0 & 0 & 0 & & & & \\
\hline \#25 & 7 & $248.7 \pm 8.5$ & 0 & $25.1 \pm 0.3$ & $23.5 \pm 4.5$ & 0 & $21.7 \pm 2.7$ & 0 & 0 & $4.1 \pm 2.0$ & 0 & & & & \\
\hline$\# 26$ & 4 & $216.1 \pm 5.5$ & 0 & $32.3 \pm 0.8$ & $16.6 \pm 0.5$ & 0 & $12.4 \pm 4.7$ & 0 & 0 & $16.6 \pm 3.6$ & 0 & & & & \\
\hline \#27 & 4 & $239.0 \pm 6.6$ & 0 & $22.5 \pm 0.5$ & $28.4 \pm 2.1$ & 0 & $18.0 \pm 6.3$ & 0 & 0 & $8.2 \pm 1.2$ & 0 & & & & \\
\hline \#28 & 5 & $237.0 \pm 4.1$ & 0 & $22.5 \pm 1.0$ & $19.2 \pm 2.8$ & 0 & $22.1 \pm 2.2$ & 0 & 0 & $17.4 \pm 1.4$ & 0 & & & & \\
\hline \#29 & 2 & $262.0 \pm 0.0$ & 0 & $23.3 \pm 1.1$ & $14.0 \pm 0.0$ & 0 & $30.9 \pm 0.2$ & $8.9 \pm 0.1$ & 0 & 0 & 0 & & & & \\
\hline \#30 & 2 & $238.5 \pm 3.5$ & 0 & $27.0 \pm 0.8$ & $27.1 \pm 1.2$ & 0 & 0 & 0 & 0 & 0 & 0 & & & & \\
\hline \#31 & 4 & $169.0 \pm 1.4$ & 0 & $24.3 \pm 1.8$ & $8.7 \pm 3.3$ & 0 & $34.8 \pm 2.7$ & 0 & 0 & $14.7 \pm 2.2$ & 0 & & & & \\
\hline \#32 & 5 & $230.0 \pm 15.5$ & 0 & $31.6 \pm 3.2$ & $11.8 \pm 1.9$ & 0 & $26.8 \pm 2.9$ & 0 & 0 & 0 & 0 & & & & \\
\hline \#33 & 4 & $191.7 \pm 8.0$ & 0 & $25.2 \pm 1.1$ & $8.7 \pm 2.2$ & 0 & $36.1 \pm 2.1$ & 0 & $9.7 \pm 0.4$ & 0 & 0 & & & & \\
\hline \#34 & 2 & $199.2 \pm 7.3$ & 0 & $33.0 \pm 0.0$ & $17.2 \pm 0.2$ & 0 & $26.1 \pm 1.9$ & 0 & 0 & 0 & 0 & & & & \\
\hline \#35 & 6 & $220.3 \pm 14.7$ & 0 & $26.1 \pm 0.8$ & $19.4 \pm 3.6$ & 0 & $22.1 \pm 1.8$ & 0 & 0 & 0 & 0 & & & & \\
\hline \#36 & 5 & $268.6 \pm 9.7$ & 0 & $27.2 \pm 1.7$ & $27.5 \pm 1.5$ & 0 & $12.4 \pm 2.3$ & 0 & 0 & $12.8 \pm 1.4$ & 0 & & & & \\
\hline \#37 & 4 & $209.3 \pm 7.0$ & 0 & $29.5 \pm 0.6$ & $9.7 \pm 2.6$ & 0 & $29.6 \pm 3.3$ & 0 & 0 & $7.9 \pm 1.5$ & 0 & & & & \\
\hline \#38 & 3 & $272.0 \pm 7.2$ & 0 & $23.3 \pm 2.0$ & $39.2 \pm 1.8$ & 0 & $18.1 \pm 2.9$ & 0 & 0 & 0 & 0 & & & & \\
\hline \#39 & 4 & $196.5 \pm 5.1$ & 0 & $23.6 \pm 0.7$ & $11.5 \pm 4.0$ & 0 & $38.2 \pm 3.3$ & 0 & 0 & 0 & 0 & & & & \\
\hline$\# 40$ & 3 & $225.5 \pm 12.6$ & 0 & $27.0 \pm 0.0$ & $17.8 \pm 2.7$ & 0 & $20.9 \pm 3.3$ & $12.1 \pm 1.0$ & 0 & 0 & 0 & & & & \\
\hline$\# 41$ & 3 & $224.0 \pm 4.6$ & 0 & $29.0 \pm 0.9$ & $34.8 \pm 2.4$ & 0 & $11.2 \pm 2.8$ & 0 & 0 & 0 & 0 & & & & \\
\hline \#42 & 3 & $226.7 \pm 5.8$ & 0 & $24.6 \pm 1.6$ & $9.1 \pm 2.9$ & 0 & $28.4 \pm 2.8$ & 0 & 0 & $17.7 \pm 0.8$ & 0 & & & & \\
\hline$\# 43$ & 4 & $200.4 \pm 14.7$ & 0 & $26.6 \pm 1.0$ & $4.4 \pm 3.3$ & 0 & $26.5 \pm 4.2$ & 0 & 0 & $14.2 \pm 3.2$ & 0 & & & & \\
\hline$\# 44$ & 3 & $248.0 \pm 10.5$ & 0 & $31.3 \pm 0.4$ & $19.3 \pm 2.8$ & 0 & $14.8 \pm 2.0$ & 0 & 0 & $12.7 \pm 2.2$ & 0 & & & & \\
\hline$\# 45$ & 4 & $204.3 \pm 3.4$ & 0 & $28.6 \pm 0.9$ & $9.2 \pm 3.6$ & 0 & $22.0 \pm 3.7$ & 0 & 0 & 0 & 0 & & & & \\
\hline$\# 46$ & 4 & $213.3 \pm 5.4$ & 0 & $26.1 \pm 2.4$ & $9.7 \pm 0.9$ & 0 & $32.5 \pm 2.2$ & 0 & $8.0 \pm 0.7$ & 0 & 0 & & & & \\
\hline \#47 & 3 & $226.7 \pm 7.1$ & 0 & $27.8 \pm 1.6$ & $26.6 \pm 2.8$ & 0 & 0 & 0 & 0 & 0 & 0 & & & & \\
\hline \#48 & 3 & $201.9 \pm 9.1$ & 0 & $31.0 \pm 3.5$ & $9.2 \pm 3.0$ & 0 & $22.8 \pm 4.5$ & 0 & 0 & $9.8 \pm 0.3$ & 0 & & & & \\
\hline$\# 49$ & 4 & $205.8 \pm 14.8$ & 0 & $28.4 \pm 0.9$ & $12.4 \pm 0.9$ & 0 & $2.7 \pm 3.1$ & 0 & 0 & $11.0 \pm 1.1$ & 0 & & & & \\
\hline
\end{tabular}

$\dagger$ Number of participants for whom the cluster was identified as the first or second best (b) / worst (w) pizza for isoenergetic substitutions

$\ddagger$ Number of participants for whom the cluster was identified as the first or second best (b) / worst (w) pizza for non-isoenergetic substitutions 


\begin{tabular}{|c|c|c|c|c|c|c|c|c|c|c|c|c|c|c|c|}
\hline \multirow[t]{2}{*}{ Cluster } & \multirow[t]{2}{*}{$\begin{array}{l}\text { Number } \\
\text { of pizzas }\end{array}$} & \multicolumn{10}{|c|}{ Average composition per $100 \mathrm{~g}$} & \multicolumn{2}{|c|}{$\begin{array}{c}\text { Isoenergetic } \\
\text { substitution } \dagger\end{array}$} & \multicolumn{2}{|c|}{$\begin{array}{c}\text { Non-Isoenergetic } \\
\text { substitution } \ddagger\end{array}$} \\
\hline & & $\begin{array}{l}\text { Energy } \\
\text { (Kcal) }\end{array}$ & $\begin{array}{l}\text { Whole } \\
\text { grains (g) }\end{array}$ & $\begin{array}{l}\text { Refined } \\
\text { grains (g) }\end{array}$ & $\begin{array}{l}\text { Dairy } \\
\text { products } \\
\text { (g) }\end{array}$ & $\begin{array}{l}\text { Green leafy } \\
\text { vegetables } \\
\text { (g) }\end{array}$ & $\begin{array}{l}\text { Other } \\
\text { vegetables } \\
\text { (g) }\end{array}$ & Fish (g) & $\begin{array}{l}\text { Red meat } \\
\text { (g) }\end{array}$ & $\begin{array}{l}\text { Processed } \\
\text { meat (g) }\end{array}$ & $\begin{array}{l}\text { Olive oil } \\
\text { (g) }\end{array}$ & $\begin{array}{l}1^{\text {st }} \text { best } \\
\text { or worst } \\
(n) \\
\end{array}$ & \begin{tabular}{|l|}
$2^{\text {nd }}$ best \\
or worst \\
(n) \\
\end{tabular} & \begin{tabular}{|l|}
$1^{15 t}$ best \\
or worst \\
$(n)$ \\
\end{tabular} & \begin{tabular}{|l}
$2^{\text {nd }}$ best \\
or worst \\
(n)
\end{tabular} \\
\hline \#50 & 2 & $210.5 \pm 4.9$ & 0 & $24.6 \pm 1.7$ & $8.2 \pm 1.7$ & 0 & $37.0 \pm 0.5$ & $12.4 \pm 0.6$ & 0 & 0 & 0 & & & & \\
\hline \#51 & 3 & $284.3 \pm 15.8$ & 0 & $29.0 \pm 1.4$ & $37.7 \pm 4.7$ & 0 & $11.9 \pm 1.1$ & 0 & 0 & 0 & 0 & & & & \\
\hline \#52 & 3 & $200.0 \pm 11.5$ & $13.1 \pm 0.9$ & $13.1 \pm 0.9$ & $11.2 \pm 1.9$ & 0 & $26.6 \pm 4.5$ & 0 & 0 & $15.4 \pm 3.5$ & 0 & & & & \\
\hline \#53 & 3 & $181.3 \pm 11.0$ & 0 & $26.9 \pm 1.2$ & $18.9 \pm 4.7$ & 0 & $19.2 \pm 0.7$ & 0 & 0 & $11.5 \pm 2.8$ & 0 & & & & \\
\hline \#54 & 2 & $202.5 \pm 16.3$ & 0 & $27.3 \pm 0.5$ & $15.4 \pm 0.1$ & $3.4 \pm 0.1$ & $19.7 \pm 0.6$ & 0 & 0 & $14.2 \pm 0.1$ & 0 & & & & \\
\hline \#55 & 6 & $226.7 \pm 11.0$ & 0 & $25.3 \pm 1.2$ & $21.4 \pm 2.1$ & $0.2 \pm 0.3$ & $15.7 \pm 2.8$ & 0 & 0 & $14.1 \pm 3.4$ & 0 & & & & \\
\hline \#56 & 2 & $210 \pm 0.0$ & 0 & $27.8 \pm 2.2$ & $19.0 \pm 0.0$ & 0 & $16.3 \pm 3.2$ & $17.0 \pm 0.0$ & 0 & 0 & 0 & & & & \\
\hline \#57 & 5 & $215.2 \pm 19.1$ & 0 & $31.2 \pm 2.9$ & $12.8 \pm 1.2$ & 0 & $10.4 \pm 5.0$ & 0 & 0 & $1.3 \pm 1.8$ & 0 & & & & \\
\hline \#58 & 3 & $229.0 \pm 21.2$ & $11.1 \pm 0.8$ & $11.1 \pm 0.8$ & $13.8 \pm 2.6$ & 0 & $36.8 \pm 0.8$ & 0 & 0 & $9.1 \pm 0.5$ & 0 & & & & \\
\hline \#59 & 3 & $226.0 \pm 13.5$ & 0 & $25.6 \pm 0.3$ & $12.8 \pm 6.1$ & 0 & $38.9 \pm 5.3$ & 0 & 0 & 0 & 0 & & & & \\
\hline$\# \mathbf{6 0}$ & 2 & $193.0 \pm 9.9$ & 0 & $32.1 \pm 0.4$ & $7.4 \pm 0.6$ & 0 & $15.0 \pm 2.1$ & $8.3 \pm 1.9$ & 0 & 0 & 0 & & & & \\
\hline$\# \mathbf{6 1}$ & 2 & $184.6 \pm 6.5$ & 0 & $29.1 \pm 1.3$ & $9.3 \pm 0.3$ & 0 & $34.3 \pm 6.6$ & 0 & 0 & 0 & 0 & & & & \\
\hline \#62 & 4 & $231.0 \pm 12.4$ & $13.9 \pm 1.1$ & $13.9 \pm 1.1$ & $13.5 \pm 1.9$ & 0 & $24.9 \pm 3.0$ & 0 & 0 & $12.6 \pm 4.1$ & 0 & & & & \\
\hline$\# 63$ & 2 & $266.1 \pm 2.6$ & 0 & $31.8 \pm 5.1$ & $25.7 \pm 3.3$ & 0 & $5.0 \pm 7.0$ & 0 & 0 & 0 & 0 & & & & \\
\hline$\# 64$ & 2 & $259.8 \pm 9.5$ & 0 & $31.2 \pm 2.5$ & $10.0 \pm 4.4$ & 0 & $20.8 \pm 2.4$ & 0 & 0 & $8.6 \pm 1.1$ & 0 & & & & \\
\hline \#65 & 2 & $244.0 \pm 0.0$ & 0 & $37.7 \pm 3.3$ & $19.5 \pm 2.1$ & 0 & $15.8 \pm 3.2$ & 0 & 0 & 0 & 0 & & & & \\
\hline$\# 66$ & 2 & $260.5 \pm 9.2$ & 0 & $28.3 \pm 0.6$ & $24.7 \pm 4.5$ & 0 & $11.4 \pm 0.2$ & 0 & $11.8 \pm 0.8$ & $3.5 \pm 4.9$ & 0 & & & & \\
\hline$\# 67$ & 2 & $245.5 \pm 12.0$ & 0 & $29.1 \pm 0.4$ & $24.6 \pm 1.2$ & 0 & $21.4 \pm 1.3$ & 0 & 0 & $1.5 \pm 2.2$ & $1.9 \pm 0.2$ & & & & \\
\hline \#68 & 2 & $214.0 \pm 2.8$ & 0 & $28.2 \pm 1.7$ & $17.8 \pm 0.4$ & 0 & $12.4 \pm 0.4$ & 0 & $14.5 \pm 1.7$ & 0 & 0 & & & & \\
\hline \#69 & 2 & $202.0 \pm 8.5$ & 0 & $25.9 \pm 3.3$ & $10.4 \pm 0.4$ & 0 & $13.8 \pm 10.5$ & 0 & $10.6 \pm 0.0$ & $1.3 \pm 1.9$ & 0 & & & & \\
\hline \#70 & 2 & $235.5 \pm 0.7$ & 0 & $30.3 \pm 0.4$ & $18.6 \pm 2.0$ & 0 & $25.4 \pm 5.2$ & 0 & 0 & $4.9 \pm 6.9$ & $0.4 \pm 0.1$ & & & & \\
\hline \#71 & 2 & $241.0 \pm 15.6$ & $13.8 \pm 0.4$ & $13.8 \pm 0.4$ & $27.0 \pm 2.3$ & 0 & $19.6 \pm 3.3$ & 0 & 0 & $5.2 \pm 7.4$ & 0 & & & & \\
\hline \#72 & 2 & $221.0 \pm 18.4$ & $7.8 \pm 0.4$ & $7.8 \pm 0.4$ & $22.5 \pm 10.1$ & 0 & $35.8 \pm 1.4$ & 0 & 0 & 0 & 0 & & & & \\
\hline \#73 & 2 & $227.5 \pm 3.5$ & $10.4 \pm 0.2$ & $10.4 \pm 0.2$ & $21.9 \pm 6.7$ & 0 & $26.1 \pm 3.3$ & 0 & 0 & $12.0 \pm 7.3$ & 0 & & & & \\
\hline \#74 & 1 & 217.0 & 0 & 30.0 & 4.0 .0 & 0 & 21.5 & 15.5 & 0 & 0 & 0 & & & & \\
\hline
\end{tabular}




\begin{tabular}{|c|c|c|c|c|c|c|c|c|c|c|c|c|c|c|c|}
\hline \multirow[t]{2}{*}{ Cluster } & \multirow[t]{2}{*}{$\begin{array}{l}\text { Number } \\
\text { of pizzas }\end{array}$} & \multicolumn{10}{|c|}{ Average composition per $100 \mathrm{~g}$} & \multicolumn{2}{|c|}{$\begin{array}{c}\text { Isoenergetic } \\
\text { substitution } \dagger\end{array}$} & \multicolumn{2}{|c|}{$\begin{array}{c}\text { Non-Isoenergetic } \\
\text { substitution } \ddagger\end{array}$} \\
\hline & & $\begin{array}{l}\text { Energy } \\
\text { (Kcal) }\end{array}$ & $\begin{array}{l}\text { Whole } \\
\text { grains (g) }\end{array}$ & $\begin{array}{l}\text { Refined } \\
\text { grains (g) }\end{array}$ & $\begin{array}{l}\text { Dairy } \\
\text { products } \\
\text { (g) }\end{array}$ & $\begin{array}{l}\text { Green leafy } \\
\text { vegetables (g) }\end{array}$ & $\begin{array}{l}\text { Other } \\
\text { vegetables } \\
\text { (g) }\end{array}$ & Fish (g) & $\begin{array}{l}\text { Red } \\
\text { meat } \\
\text { (g) }\end{array}$ & $\begin{array}{l}\text { Processed } \\
\text { meat }(g)\end{array}$ & $\begin{array}{l}\text { Olive oil } \\
\text { (g) }\end{array}$ & $\begin{array}{l}1^{\text {st }} \text { best or } \\
\text { worst }(n)\end{array}$ & $\begin{array}{l}2^{\text {nd }} \text { best } \\
\text { or worst } \\
(n)\end{array}$ & $\begin{array}{l}1^{\text {st }} \text { best or } \\
\text { worst }(n)\end{array}$ & $\begin{array}{l}2^{\text {nd }} \text { best } \\
\text { or worst } \\
\text { (n) }\end{array}$ \\
\hline \#75 & 1 & 221.0 & 0 & 24.6 & 10.9 & 0 & 31.3 & 16.8 & 0 & 0 & 0 & & & & \\
\hline \#76 & 1 & 201.0 & 9.0 & 9.0 & 14.0 & 0 & 37.1 & 0 & 0 & 11.9 & 0 & & & & \\
\hline \#77 & 1 & 196.0 & 0 & 27.6 & 25.1 & 0 & 11.6 & 11.3 & 0 & 0 & 0 & & & & \\
\hline \#78 & 1 & 269.0 & 0 & 25.1 & 32.3 & 0 & 0.7 & 0 & 0 & 25.1 & 0 & $820^{w}$ & $60^{w}$ & $19^{w}$ & $789 w$ \\
\hline \#79 & 1 & 280.0 & 0 & 27.0 & 16.0 & 0 & 0 & 0 & 0 & 18.7 & 0 & & & & \\
\hline$\# \mathbf{8 0}$ & 1 & 220.0 & 0 & 22.2 & 13.9 & 0 & 12.0 & 0 & 0 & 0 & 0 & & & & \\
\hline \#81 & 1 & 231.0 & 0 & 30.0 & 6.5 & 0 & 35.5 & 0 & 0 & 7.5 & 0.5 & & & & \\
\hline$\# 82$ & 1 & 178.0 & 0 & 25.4 & 13.8 & 0 & 25.1 & 9.2 & 0 & 0 & 0 & & & & $5^{b}$ \\
\hline$\# 83$ & 1 & 210.0 & 0 & 25.8 & 9.1 & 0 & 17.7 & 4.6 & 0 & 0 & 0 & & & & \\
\hline$\# 84$ & 1 & 320.0 & 0 & 19.8 & 29.0 & 0 & 12.2 & 0 & 0 & 24.5 & 0 & $60^{w}$ & $818^{w}$ & $861^{w}$ & $19^{w}$ \\
\hline$\# 85$ & 1 & 290.0 & 0 & 21.6 & 27.6 & 0 & 20.4 & 0 & 0 & 12.2 & 0 & & & & \\
\hline$\# 86$ & 1 & 220.0 & 0 & 28.2 & 23.3 & 0 & 28.6 & 0 & 0 & 0 & 1.1 & & & & \\
\hline$\# 87$ & 1 & 251.0 & 0 & 27.0 & 33.3 & 0 & 18.7 & 0 & 0 & 0 & 1.3 & & & & \\
\hline$\# \mathbf{8 8}$ & 1 & 190.0 & 14.1 & 14.1 & 11.7 & 0 & 27.6 & 0 & 0 & 0 & 0 & $850^{b}$ & $9^{b}$ & $879^{b}$ & $1^{\mathrm{b}}$ \\
\hline \#89 & 1 & 210.0 & 12.3 & 12.3 & 14.2 & 0 & 7.1 & 0 & 0 & 0 & 0 & & $44^{\mathrm{b}}$ & & $253^{b}$ \\
\hline$\# 90$ & 1 & 210.0 & 0 & 28.8 & 3.2 & 0 & 25.5 & 0 & 15.5 & 0 & 0 & & & & \\
\hline$\# 91$ & 1 & 252.0 & 8.4 & 8.4 & 40.0 & 0 & 28.8 & 0 & 0 & 0 & 0 & & & & \\
\hline$\# 92$ & 1 & 211.0 & 0 & 25.8 & 13.1 & 0 & 33.2 & 0 & 0 & 6.8 & 1.7 & & & & \\
\hline$\# 93$ & 1 & 255.0 & 0 & 31.7 & 17.0 & 0 & 22.3 & 0 & 6.7 & 0 & 0 & & & & \\
\hline$\# 94$ & 1 & 293.0 & 12.6 & 12.6 & 21.2 & 0 & 3.5 & 0 & 0 & 10.7 & 0 & & & & \\
\hline \#95 & 1 & 191.0 & 0 & 28.2 & 4.9 & 2.4 & 37.1 & 0 & 0 & 0 & 0 & & & & $390^{\mathrm{b}}$ \\
\hline$\# 96$ & 1 & 235.0 & 0 & 27.0 & 35.2 & 3.3 & 6.6 & 0 & 0 & 0 & 0 & & & & \\
\hline$\# 97$ & 1 & 250.0 & 0 & 29.4 & 36.2 & 0 & 0 & 10.7 & 0 & 0 & 0 & & & & \\
\hline \#98 & 1 & 203.0 & 0 & 23.4 & 10.4 & 5.2 & 45.4 & 0 & 0 & 0 & 0 & & & & $21^{b}$ \\
\hline \#99 & 1 & 354.0 & 12.3 & 12.3 & 15.9 & 0 & 25.7 & 0 & 11.5 & 0 & 0 & $14^{\mathrm{b}}$ & $5^{b}$ & & $72^{w}$ \\
\hline$\# 100$ & 1 & 227.0 & 0 & 31.2 & 15.0 & 9.0 & 24.0 & 0 & 0 & 0 & 0 & $8^{\mathbf{b}}$ & $676^{\mathrm{b}}$ & $1^{\mathbf{b}}$ & $210^{b}$ \\
\hline
\end{tabular}

$\dagger$ Number of participants for whom the cluster was identified as the first or second best (b) / worst (w) pizza for isoenergetic substitutions

$\ddagger$ Number of participants for whom the cluster was identified as the first or second best (b) / worst (w) pizza for non-isoenergetic substitutions 
Supplemental table 2 Nutritional characteristics of mixed dishes used for inter-categories substitutions

\begin{tabular}{|c|c|c|c|c|c|c|c|c|c|c|c|c|c|}
\hline \multirow[b]{2}{*}{ Mixed dish name } & \multicolumn{13}{|c|}{ Proportion per $100 \mathrm{~g}$} \\
\hline & $\begin{array}{l}\text { Energy } \\
\text { (Kcal) }\end{array}$ & $\begin{array}{l}\text { Refined } \\
\text { grains } \\
\text { (g) }\end{array}$ & $\begin{array}{l}\text { Green leafy } \\
\text { vegetables } \\
\text { (g) }\end{array}$ & $\begin{array}{l}\text { Other } \\
\text { vegetables } \\
\text { (g) }\end{array}$ & $\begin{array}{l}\text { Fruit } \\
\text { (g) }\end{array}$ & $\begin{array}{l}\text { Dairy } \\
\text { products } \\
\text { (g) }\end{array}$ & $\begin{array}{l}\text { Fish } \\
\text { (g) }\end{array}$ & $\begin{array}{l}\text { Eggs } \\
\text { (g) }\end{array}$ & $\begin{array}{l}\text { Red } \\
\text { meat (g) }\end{array}$ & $\begin{array}{l}\text { Processed } \\
\text { meat (g) }\end{array}$ & $\begin{array}{l}\text { Potatoes } \\
\text { (g) }\end{array}$ & $\begin{array}{l}\text { Butter } \\
\text { (g) }\end{array}$ & $\begin{array}{l}\text { Olive } \\
\text { oil (g) }\end{array}$ \\
\hline Canned cassoulet & 136 & 1 & 0 & 5 & 0 & 0 & 0 & 0 & 6 & 20 & 0 & 0 & 0 \\
\hline Canned sauerkraut & 110 & 0 & 0 & 27.5 & 0 & 0 & 0 & 0 & 7.5 & 14 & 10 & 0 & 0 \\
\hline Shepherd's pie & 145 & 2.3 & 0 & 19 & 0 & 26 & 0 & 0 & 13 & 0 & 8 & 7.5 & 0 \\
\hline Sausages with lentils & 131 & 0.5 & 0 & 4 & 0 & 0 & 0 & 0 & 13 & 13 & 0 & 0 & 0 \\
\hline Pot-au-feu & 72.3 & 0 & 0 & 36.3 & 0 & 0 & 0 & 0 & 52.5 & 0 & 10.6 & 0 & 0 \\
\hline Meat ravioli with tomato sauce (canned product) & 97.4 & 54.5 & 0 & 26.7 & 0 & 0 & 0 & 0 & 10 & 0 & 0 & 0 & 0.3 \\
\hline Garnished mutton couscous & 148 & 30.5 & 0 & 26.5 & 0 & 0 & 0 & 0 & 30 & 0 & 0 & 0 & 1.5 \\
\hline Paella & 169 & 50.5 & 0 & 14 & 0 & 0 & 6 & 0 & 0 & 3 & 0 & 0 & 0 \\
\hline Potato gratin & 110 & 0 & 0 & 0 & 0 & 26.9 & 0 & 7.5 & 0 & 0 & 62 & 3.1 & 0 \\
\hline Milanese “osso bucco” & 102 & 3.1 & 0 & 23.2 & 0 & 0 & 0 & 0 & 37 & 0 & 0 & 0 & 2.8 \\
\hline Hotpot from Auvergne (pork, sausages and vegetable) & 88.4 & 0 & 0 & 40 & 0 & 0 & 0 & 0 & 20 & 8 & 23 & 0 & 0 \\
\hline Cannelloni with meat & 154 & 22.8 & 0 & 25.3 & 0 & 12.7 & 0 & 0 & 25 & 0 & 1.5 & 0.3 & 0.3 \\
\hline Lasagne with bolognese sauce & 140 & 44.0 & 0 & 14.6 & 0 & 11.8 & 0 & 0 & 13.5 & 0 & 0 & 0.2 & 0.1 \\
\hline Pasta bolognese & 137 & 57 & 0 & 25.4 & 0 & 0 & 0 & 0 & 10 & 0 & 0 & 0 & 0 \\
\hline Fried rice & 141 & 61 & 0 & 15 & 0 & 0 & 0 & 10 & 0 & 9 & 0 & 0 & 0 \\
\hline Basque chicken with rice & 101 & 1 & 0 & 28.4 & 0 & 0 & 0 & 0 & 0 & 0 & 0 & 0 & 0 \\
\hline Basque chicken with pasta & 96.6 & 9.4 & 0 & 21.6 & 0 & 0 & 0 & 0 & 0 & 0 & 0 & 0 & 0 \\
\hline Spaghetti with tomato sauce & 67.4 & 47.5 & 0 & 13 & 0 & 0 & 0 & 0 & 0 & 0 & 0 & 0 & 0 \\
\hline Baked pasta & 150 & 56.2 & 0 & 0 & 0 & 21.5 & 0 & 15 & 0 & 7 & 0 & 0 & 0 \\
\hline Moussaka & 138 & 3.4 & 0 & 47 & 0 & 22.2 & 0 & 0 & 17 & 0 & 0 & 0.5 & 0 \\
\hline Lamb stew & 139 & 1.5 & 0 & 41.4 & 0 & 0 & 0 & 0 & 47 & 0 & 0 & 0 & 0 \\
\hline Royal couscous with meat & 149 & 31 & 0 & 28 & 0 & 0 & 0 & 0 & 10 & 5 & 0 & 0 & 1.5 \\
\hline Endive gratin with ham & 90.9 & 1.4 & 0 & 31.6 & 0 & 41.7 & 0 & 0 & 0 & 23.5 & 0 & 1 & 0 \\
\hline Pasta carbonara & 166 & 74.9 & 0 & 0 & 0 & 12 & 0 & 5 & 0 & 8 & 0 & 0 & 0 \\
\hline Tartiflette & 144 & 0 & 0 & 4 & 0 & 31 & 0 & 0 & 0 & 3 & 61 & 0 & 0 \\
\hline Chicken couscous & 158 & 31 & 0 & 29 & 0 & 0 & 0 & 0 & 0 & 0 & 0 & 0 & 1.5 \\
\hline Cheese ravioli & 209 & 21.5 & 0 & 0 & 0 & 32.5 & 0 & 9 & 0 & 0 & 2 & 0 & 0 \\
\hline Vegetable gratin & 107 & 1.9 & 0 & 81.7 & 0 & 5.3 & 0 & 3.2 & 0 & 0 & 0 & 1.07 & 0 \\
\hline Croque-monsieur (toasted ham and cheese sandwich) & 290 & 25.6 & 0 & 0 & 0 & 28.7 & 0 & 0 & 0 & 24 & 0 & 0.2 & 0 \\
\hline Hot-dog & 318 & 32.6 & 0 & 3 & 0 & 0 & 0 & 0 & 0 & 50 & 0 & 0 & 0 \\
\hline French quiche Lorraine & 292 & 21 & 0 & 0 & 0 & 48.4 & 0 & 10 & 0 & 11 & 0 & 3 & 0 \\
\hline
\end{tabular}




\begin{tabular}{|c|c|c|c|c|c|c|c|c|c|c|c|c|c|}
\hline Hamburger & 216 & 26.1 & 3.5 & 10.5 & 0 & 2.1 & 0 & 0 & 39.5 & 0 & 0 & 0 & 0 \\
\hline Cheeseburger & 262 & 28.8 & 2.5 & 4.5 & 0 & 22.3 & 0 & 0 & 23 & 0 & 0 & 0 & 0 \\
\hline Double cheeseburger & 297 & 24.6 & 5.5 & 7.5 & 0 & 24 & 0 & 0 & 25 & 0 & 0 & 0 & 0 \\
\hline Vegetable pie & 237 & 22.1 & 7.5 & 30 & 0 & 28 & 0 & 8 & 0 & 0 & 0 & 4.3 & 0 \\
\hline Spring rolls & 116 & 20.4 & 9 & 41 & 0 & 0 & 0 & 0 & 0 & 0 & 0 & 0 & 0 \\
\hline Kebab and raw vegetable & 233 & 17.7 & 7 & 26.2 & 0 & 0 & 0 & 0 & 43 & 0 & 0 & 0 & 0 \\
\hline Tuna and raw vegetable sandwich & 274 & 43.9 & 2.7 & 12.6 & 0 & 0 & 19.3 & 0.9 & 0 & 0 & 0 & 0 & 0 \\
\hline Ham panini with mozzarella and tomatoes & 243 & 28.9 & 5 & 16 & 0 & 20.9 & 0 & 0 & 0 & 16.5 & 0 & 0 & 0 \\
\hline Cheese pie or quiche & 263 & 22.4 & 0 & 0 & 0 & 48.5 & 0 & 16 & 0 & 0 & 0 & 8.8 & 0 \\
\hline Ham sandwich with boiled egg and raw vegetable & 222 & 42.5 & 4.7 & 14.2 & 0 & 0 & 0 & 6.7 & 0 & 21 & 0 & 4.3 & 0 \\
\hline Chicken and raw vegetable sandwich & 258 & 41.5 & 4 & 13 & 0 & 0 & 0 & 0.8 & 0 & 0 & 0 & 0 & 0 \\
\hline Smoked salmon, and butter sandwich & 265 & 57.2 & 0 & 0 & 5.2 & 0 & 19.5 & 0 & 0 & 0 & 0 & 3.3 & 0 \\
\hline Chicken vol-au-vent with fish and seafood & 208 & 7.9 & 0 & 17 & 0 & 37.2 & 16 & 0 & 0 & 0 & 0 & 2.7 & 0 \\
\hline Chicken nugget & 188 & 9.2 & 0 & 0 & 0 & 0 & 0 & 19.4 & 0 & 0 & 0 & 0 & 0 \\
\hline Pan bagnat & 245 & 32.7 & 0 & 30 & 0 & 0 & 8.7 & 5 & 0 & 0 & 0 & 0 & 10.2 \\
\hline Ham and butter sandwich & 283 & 47.7 & 0 & 0 & 0 & 0 & 0 & 0 & 0 & 30 & 0 & 10 & 0 \\
\hline Cheese and butter sandwich & 339 & 47.7 & 0 & 0 & 0 & 30 & 0 & 0 & 0 & 0 & 0 & 10 & 0 \\
\hline Pâté and pickle sandwich & 299 & 41.3 & 0 & 0 & 0 & 0 & 0 & 0.9 & 9.4 & 0 & 0.4 & 0 & 0 \\
\hline Butter and dry sausage sandwich & 375 & 47.7 & 0 & 0 & 0 & 0 & 0 & 0 & 0 & 30 & 0 & 10 & 0 \\
\hline Ham sandwich with emmental and butter & 309 & 42.1 & 0 & 0 & 0 & 13 & 0 & 0 & 0 & 25 & 0 & 9 & 0 \\
\hline Sandwich with raw vegetable and mayonnaise & 221 & 39.9 & 0 & 37 & 0 & 0 & 0 & 0.9 & 0 & 0 & 0 & 0 & 0 \\
\hline Turkey sandwich with raw vegetable & 255 & 43.1 & 2 & 11 & 0 & 0 & 0 & 1.1 & 0 & 0 & 0 & 0 & 0 \\
\hline Egg and raw vegetable sandwich & 247 & 43.9 & 2.7 & 12.6 & 0 & 0 & 0 & 20.2 & 0 & 0 & 0 & 0 & 0 \\
\hline Pork and raw vegetable sandwich & 267 & 43.1 & 2 & 11 & 0 & 0 & 0 & 1.1 & 19 & 0 & 0 & 0 & 0 \\
\hline Sandwich with merguez, ketchup and mustard & 282 & 39.7 & 0 & 0 & 0 & 0 & 0 & 0 & 0 & 42 & 0 & 0 & 0 \\
\hline Salami and butter sandwich & 379 & 47.7 & 0 & 0 & 0 & 0 & 0 & 0 & 0 & 30 & 0 & 10 & 0 \\
\hline $\begin{array}{l}\text { Croque-madame (toasted ham and cheese sandwich } \\
\text { topped with a fried egg) }\end{array}$ & 264 & 20.3 & 0 & 0 & 0 & 25.3 & 0 & 17.9 & 0 & 19 & 0 & 0.1 & 0 \\
\hline Flamenkueche (salted pie with bacon) & 263 & 34 & 0 & 16 & 0 & 18 & 0 & 0.6 & 17 & 11.2 & 0 & 0 & 0 \\
\hline $\begin{array}{l}\text { Stuffed pancake with bechamel, ham, cheese and } \\
\text { mushroom }\end{array}$ & 145 & 14 & 0 & 20 & 0 & 48.1 & 0 & 7.9 & 0 & 7 & 0 & 0.8 & 0 \\
\hline Leek pie & 258 & 24.2 & 0 & 18.2 & 0 & 43.8 & 0 & 0 & 0 & 0 & 0 & 4.1 & 0 \\
\hline Tomato pie & 218 & 25.2 & 0 & 45.5 & 0 & 8 & 0 & 4 & 0 & 0 & 0 & 4.9 & 0.8 \\
\hline Salmon and sorrel pie & 230 & 21.7 & 14.5 & 16 & 0 & 33.1 & 17 & 0 & 0 & 0 & 0 & 4.5 & 0 \\
\hline Tuna salad with vegetable (canned product) & 123 & 0.3 & 0 & 57.6 & 0 & 0 & 24.92 & 0 & 0 & 0 & 0 & 0 & 1.3 \\
\hline Potato salad & 127 & 0.4 & 0 & 22 & 0 & 0 & 2.7 & 4.7 & 0 & 2 & 54.5 & 0 & 0 \\
\hline
\end{tabular}


Couscous salad

Rice salad

Vegetarian pasta salad
130

50
54.7

54.7

0
0

0

26

35.5

0.5

0

0
0
0

$\begin{array}{lll}0 & 0 & 0 \\ 10.6 & 7.7 & 0 \\ 0 & 0\end{array}$

$\begin{array}{ll}0 & 0 \\ 0 & 0 \\ 0 & \end{array}$

0
0
0

0

$0 \quad 0$

$0 \quad 0$


Supplemental table 3 Rates of change in risk of type 2 diabetes (percentage) in population subgroups for substitutions with the best and worst pizzas

\begin{tabular}{lllcr}
\hline Population & \multicolumn{2}{c}{ Isoenergetic substitution } & \multicolumn{2}{c}{ Non-isoenergetic substitution } \\
\cline { 2 - 5 } & Men & Women & Men & Women \\
\hline
\end{tabular}

Age $<45$ years

Age $\geq 45$ years

Body mass index $<25$

Body mass index $\geq 25$

Fruit and vegetables consumption $<400 \mathrm{~g} /$ day

Fruit and vegetables consumption $\geq 400 \mathrm{~g} / \mathrm{day}$

Low adherence to the mPNNS-GS

Medium adherence to the mPNNS-GS

High adherence to the mPNNS-GS

Low adherence to the MEDI-LITE

Medium adherence to the MEDI-LITE

High adherence to the MEDI-LITE

Low adherence to the provegetarian FP

Medium adherence to the provegetarian FP

High adherence to the provegetarian FP

$1^{\text {st }}$ Best pizza (\#88)

$\begin{array}{ll}-4.2(-5.2 ;-3.1) & -1.9(-2.4 ;-1.4) \\ -1.4(-1.7 ;-1.0) & -0.9(-1.1 ;-0.6) \\ -3.2(-4.0 ;-2.4) & -1.5(-1.9 ;-1.1) \\ -2.0(-2.5 ;-1.5) & -1.2(-1.5 ;-0.8) \\ -3.0(-3.7 ;-2.2) & -1.6(-2.0 ;-1.2) \\ -1.7(-2.2 ;-1.3) & -0.9(-1.1 ;-0.6) \\ -3.3(-4.1 ;-2.4) & -1.5(-1.8 ;-1.1) \\ -2.1(-2.6 ;-1.5) & -1.6(-2.1 ;-1.2) \\ -2.4(-3.0 ;-1.8) & -1.2(-1.5 ;-0.9) \\ -3.0(-3.7 ;-2.2) & -1.5(-1.9 ;-1.1) \\ -2.9(-3.6 ;-2.1) & -1.5(-1.9 ;-1.1) \\ -2.0(-2.5 ;-1.5) & -1.2(-1.5 ;-0.9) \\ -2.8(-3.6 ;-2.1) & -1.4(-1.8 ;-1.1) \\ -2.6(-3.3 ;-1.9) & -1.3(-1.6 ;-1.0) \\ -2.3(-2.9 ;-1.7) & -1.4(-1.8 ;-1.1)\end{array}$

\section{$2^{\text {nd }}$ Best pizza (\#100)}

Age $<45$ years

Age $\geq 45$ years

Body mass index $<25$

Body mass index $\geq 25$

Fruit and vegetables consumption $<400 \mathrm{~g} /$ day

Fruit and vegetables consumption $\geq 400 \mathrm{~g} / \mathrm{day}$

Low adherence to the mPNNS-GS

Medium adherence to the mPNNS-GS

High adherence to the mPNNS-GS

Low adherence to the MEDI-LITE

Medium adherence to the MEDI-LITE

High adherence to the MEDI-LITE

Low adherence to the provegetarian FP

Medium adherence to the provegetarian FP

High adherence to the provegetarian FP
$-3.6(-5.3 ;-1.8)$

$-1.2(-1.8 ;-0.6)$

$-2.8(-4.2 ;-1.4)$

$-1.8(-2.7 ;-0.9)$

$-2.6(-3.9 ;-1.3)$

$-1.5(-2.2 ;-0.7)$

$-2.9(-4.3 ;-1.4)$

$-1.8(-2.7 ;-0.9)$

$-2.1(-3.2 ;-1.0)$

$-2.6(-3.9 ;-1.3)$

$-2.5(-3.8 ;-1.2)$

$-1.7(-2.6 ;-0.8)$

$-2.5(-3.8 ;-1.2)$

$-2.3(-3.5 ;-1.1)$

$-2.0(-3.0 ;-1.0)$
$-1.7(-2.5 ;-0.8)$

$-0.8(-1.1 ;-0.4)$

$-1.3(-2.0 ;-0.7)$

$-1.0(-1.5 ;-0.5)$

$-1.4(-2.2 ;-0.7)$

$-0.7(-1.1 ;-0.3)$

$-1.3(-1.9 ;-0.6)$

$-1.5(-2.2 ;-0.7)$

$-1.0(-1.5 ;-0.5)$

$-1.4(-2.0 ;-0.7)$

$-1.3(-1.9 ;-0.6)$

$-1.0(-1.5 ;-0.5)$

$-1.3(-2.0 ;-0.7)$

$-1.1(-1.7 ;-0.6)$

$-1.2(-1.8 ;-0.6)$

$\begin{array}{ll}-5.4(-7.0 ;-3.7) & -2.4(-3.3 ;-1.4) \\ -2.0(-2.4 ;-1.5) & -1.3(-1.6 ;-0.9) \\ -3.2(-4.7 ;-1.7) & -1.5(-2.3 ;-0.6) \\ -3.3(-3.8 ;-2.6) & -2.0(-2.4 ;-1.6) \\ -4.1(-5.1 ;-2.9) & -2.3(-3.0 ;-1.5) \\ -2.4(-3.0 ;-1.8) & -1.2(-1.6 ;-0.8) \\ -4.5(-5.7 ;-3.1) & -2.0(-2.6 ;-1.3) \\ -2.9(-3.6 ;-2.2) & -2.3(-3.0 ;-1.5) \\ -3.3(-4.2 ;-2.4) & -1.7(-2.1 ;-1.1) \\ -4.1(-5.2 ;-2.9) & -2.2(-2.9 ;-1.5) \\ -4.0(-5.0 ;-2.9) & -2.0(-2.7 ;-1.3) \\ -2.8(-3.5 ;-2.0) & -1.6(-2.1 ;-1.0) \\ -4.0(-5.0 ;-2.9) & -2.1(-2.8 ;-1.4) \\ -3.7(-4.6 ;-2.7) & -1.9(-2.4 ;-1.3) \\ -3.2(-4.0 ;-2.3) & -1.9(-2.4 ;-1.2)\end{array}$

-3.6 (-5.3; -1.8)

$-1.6(-2.5 ;-0.8)$

$-1.2(-1.8 ;-0.6)$

$-0.7(-1.1 ;-0.3)$

$-2.8(-4.2 ;-1.4)$

$-1.8(-2.7 ;-0.9)$

$-2.6(-3.9 ;-1.3)$

$-1.5(-2.2 ;-0.7)$

$-2.9(-4.3 ;-1.4)$

$-1.8(-2.7 ;-0.8)$

$-2.1(-3.1 ;-1.0)$

$-2.6(-3.9 ;-1.3)$

$-2.5(-3.7 ;-1.2)$

$-1.7(-2.6 ;-0.8)$

$-2.5(-3.7 ;-1.2)$

$-2.4(-3.5 ;-1.2)$

$-2.0(-3.0 ;-0.9)$

$-1.3(-2.0 ;-0.7)$

$-1.0(-1.5 ;-0.5)$

$-1.4(-2.1 ;-0.7)$

$-0.7(-1.1 ;-0.3)$

$-1.3(-1.9 ;-0.6)$

$-1.4(-2.2 ;-0.7)$

$-1.0(-1.5 ;-0.5)$

$-1.4(-2.0 ;-0.7)$

$-1.2(-1.9 ;-0.6)$

$-1.0(-1.5 ;-0.5)$

$-1.3(-2.0 ;-0.6)$

$-1.1(-1.7 ;-0.5)$

$-1.2(-1.8 ;-0.6)$

$\begin{array}{lll}\text { Age }<\mathbf{4 5} \text { years } & 4.1(2.9 ; 5.4) & 1.9(1.3 ; 2.4) \\ \text { Age } \geq \mathbf{4 5} \text { years } & 1.3(0.9 ; 1.7) & 0.8(0.5 ; 1.0) \\ \text { Body mass index }<\mathbf{2 5} & 3.2(2.2 ; 4.2) & 1.5(1.1 ; 2.0) \\ \text { Body mass index } \geq \mathbf{2 5} & 2.1(1.4 ; 2.7) & 1.1(0.8 ; 1.4) \\ \text { Fruit and vegetables consumption }<\mathbf{4 0 0 g} \text { /day } & 2.9(2.0 ; 3.8) & 1.5(1.1 ; 2.0) \\ \text { Fruit and vegetables consumption } \geq \mathbf{4 0 0 g} / \mathbf{d a y} & 1.8(1.2 ; 2.3) & 0.8(0.6 ; 1.1) \\ \text { Low adherence to the mPNNS-GS } & 3.3(2.3 ; 4.2) & 1.5(1.0 ; 1.9) \\ \text { Medium adherence to the mPNNS-GS } & 2.0(1.4 ; 2.6) & 1.6(1.1 ; 2.1) \\ \text { High adherence to the mPNNS-GS } & 2.5(1.7 ; 3.3) & 1.1(0.8 ; 1.4) \\ \text { Low adherence to the MEDI-LITE } & 2.8(2.0 ; 3.7) & 1.5(1.0 ; 1.9) \\ \text { Medium adherence to the MEDI-LITE } & 2.9(2.0 ; 3.8) & 1.4(1.0 ; 1.8) \\ \text { High adherence to the MEDI-LITE } & 2.1(1.5 ; 2.7) & 1.2(0.8 ; 1.5) \\ \text { Low adherence to the provegetarian FP } & 2.8(1.9 ; 3.6) & 1.4(1.0 ; 1.9) \\ \text { Medium adherence to the provegetarian FP } & 2.6(1.8 ; 3.5) & 1.3(0.9 ; 1.6) \\ \text { High adherence to the provegetarian FP } & 2.4(1.6 ; 3.1) & 1.3(0.9 ; 1.7)\end{array}$

$\begin{array}{ll}5.7(3.7 ; 7.7) & 2.6(1.3 ; 3.7) \\ 2.1(1.5 ; 2.7) & 1.3(0.9 ; 1.7) \\ 3.2(1.3 ; 5.0) & 1.4(0.3 ; 2.5) \\ 3.5(2.8 ; 4.3) & 2.2(1.7 ; 2.6) \\ 4.3(2.9 ; 5.7) & 2.4(1.4 ; 3.3) \\ 2.7(1.9 ; 3.4) & 1.3(0.8 ; 1.7) \\ 4.8(3.1 ; 6.3) & 2.2(1.2 ; 3.0) \\ 3.1(2.2 ; 3.9) & 2.5(1.5 ; 3.4) \\ 3.6(2.5 ; 4.7) & 1.7(1.1 ; 2.3) \\ 4.3(2.9 ; 5.6) & 2.4(1.5 ; 3.2) \\ 4.4(3.0 ; 5.7) & 2.1(1.2 ; 2.9) \\ 3.0(2.1 ; 3.9) & 1.7(1.0 ; 2.3) \\ 4.2(2.9 ; 5.5) & 2.3(1.4 ; 3.1) \\ 4.0(2.7 ; 5.1) & 2.0(1.2 ; 2.6) \\ 3.4(2.3 ; 4.4) & 1.9(1.1 ; 2.7)\end{array}$


$2^{\text {nd }}$ Worst pizza (\#84)

$\begin{array}{lllll}\text { Age }<45 \text { years } & 3.5(2.4 ; 4.7) & 1.6(1.1 ; 2.2) & 7.3(3.4 ; 10.6) & 3.2(0.8 ; 5.4) \\ \text { Age } \geq \mathbf{4 5} \text { years } & 1.2(0.8 ; 1.5) & 0.7(0.5 ; 0.9) & 2.9(1.9 ; 3.8) & 1.9(1.0 ; 2.6) \\ \text { Body mass index }<\mathbf{2 5} & 2.7(1.8 ; 3.6) & 1.3(0.9 ; 1.8) & 2.8(-0.7 ; 6.4) & 1.2(-1.0 ; 3.4) \\ \text { Body mass index } \geq \mathbf{2 5} & 1.8(1.2 ; 2.4) & 0.9(0.6 ; 1.2) & 5.1(4.0 ; 6.1) & 3.3(2.6 ; 4.0) \\ \text { Fruit and vegetables consumption }<\mathbf{4 0 0 g} / \mathbf{d a y} & 2.5(1.7 ; 3.3) & 1.3(0.9 ; 1.8) & 5.7(3.1 ; 7.9) & 3.3(1.3 ; 4.9) \\ \text { Fruit and vegetables consumption } \geq \mathbf{4 0 0 g} / \mathbf{d a y} & 1.6(1.1 ; 2.1) & 0.8(0.6 ; 1.0) & 3.6(2.3 ; 4.8) & 1.8(0.8 ; 2.6) \\ \text { Low adherence to the mPNNS-GS } & 2.7(1.8 ; 3.6) & 1.3(0.8 ; 1.7) & 6.2(3.2 ; 8.8) & 2.8(1.0 ; 4.4) \\ \text { Medium adherence to the mPNNS-GS } & 1.7(1.2 ; 2.3) & 1.4(0.9 ; 1.8) & 4.2(2.5 ; 5.6) & 3.4(1.4 ; 5.0) \\ \text { High adherence to the mPNNS-GS } & 2.2(1.5 ; 2.9) & 1.0(0.7 ; 1.3) & 4.8(2.9 ; 6.5) & 2.4(1.1 ; 3.4) \\ \text { Low adherence to the MEDI-LITE } & 2.4(1.6 ; 3.1) & 1.2(0.8 ; 1.6) & 5.7(3.1 ; 7.9) & 3.3(1.6 ; 4.7) \\ \text { Medium adherence to the MEDI-LITE } & 2.5(1.7 ; 3.4) & 1.2(0.8 ; 1.6) & 5.9(3.4 ; 7.9) & 2.9(1.0 ; 4.4) \\ \text { High adherence to the MEDI-LITE } & 1.9(1.3 ; 2.5) & 1.1(0.7 ; 1.4) & 4.0(2.4 ; 5.5) & 2.3(0.9 ; 3.4) \\ \text { Low adherence to the provegetarian FP } & 2.3(1.5 ; 3.1) & 1.2(0.8 ; 1.6) & 5.6(3.2 ; 7.7) & 3.2(1.4 ; 4.6) \\ \text { Medium adherence to the provegetarian FP } & 2.3(1.5 ; 3.0) & 1.1(0.8 ; 1.5) & 5.3(3.1 ; 7.1) & 2.7(1.2 ; 3.9) \\ \text { High adherence to the provegetarian FP } & 2.1(1.5 ; 2.8) & 1.2(0.8 ; 1.6) & 4.5(2.5 ; 6.2) & 2.6(0.8 ; 4.0)\end{array}$

MEDI-LITE, Literature-based adherence score to the Mediterranean diet; mPNNS-GS, modified Programme National Nutrition Santé Guideline Score; NIE substitution, Non-isoenergetic substitution; Provegetarian FP, Provegetarian food pattern. "Pizza" here stands for cluster of pizzas ( $n=100$, out of 353 pizzas). 
Supplemental table 4 Rates of change in risk of type 2 diabetes (in percentage) for inter-categories substitutions in the whole population and in population subgroups $\dagger$

\begin{tabular}{|c|c|c|c|c|}
\hline \multirow[t]{2}{*}{ Population } & \multicolumn{2}{|c|}{ Isoenergetic substitution } & \multicolumn{2}{|c|}{ Non-isoenergetic substitution } \\
\hline & Men & Women & Men & Women \\
\hline \multicolumn{5}{|c|}{ Pan bagnat } \\
\hline Whole population & $-2.6(-3.7 ;-1.5)$ & $-1.4(-1.9 ;-0.8)$ & $-2.1(-3.2 ;-1.0)$ & $-1.1(-1.7 ;-0.4)$ \\
\hline Pizza consumers & $-6.5(-9.1 ;-3.9)$ & $-4.3(-6.0 ;-2.5)$ & $-5.4(-8.1 ;-2.6)$ & $-3.4(-5.3 ;-1.4)$ \\
\hline Participants who consumed pizza once & $-5.0(-7.0 ;-3.0)$ & $-3.7(-5.2 ;-2.2)$ & $-4.1(-6.2 ;-1.9)$ & $-2.9(-4.6 ;-1.2)$ \\
\hline Participants who consumed pizza twice & $-9.6(-13.3 ;-5.7)$ & $-6.2(-8.6 ;-3.7)$ & $-8.0(-12.0 ;-3.9)$ & $-5.3(-8.2 ;-2.4)$ \\
\hline Participants who consumed pizza more than twice & $-13.5(-18.6 ;-8.0)$ & $-9.7(-13.4 ;-5.8)$ & $-11.6(-17.0 ;-5.8)$ & $-7.7(-11.9 ;-3.4)$ \\
\hline Age $<45$ years & $-4.1(-5.7 ;-2.4)$ & $-1.9(-2.6 ;-1.1)$ & $-3.5(-5.2 ;-1.7)$ & $-1.6(-2.5 ;-0.7)$ \\
\hline Age $\geq 45$ years & $-1.4(-1.9 ;-0.8)$ & $-0.9(-1.2 ;-0.5)$ & $-1.0(-1.6 ;-0.4)$ & $-0.6(-1.0 ;-0.2)$ \\
\hline Body mass index $<25$ & $-3.2(-4.5 ;-1.9)$ & $-1.5(-2.1 ;-0.9)$ & $-3.2(-4.6 ;-1.7)$ & $-1.6(-2.3 ;-0.8)$ \\
\hline Body mass index $\geq 25$ & $-2.1(-2.9 ;-1.2)$ & $-1.2(-1.6 ;-0.7)$ & $-1.5(-2.3 ;-0.6)$ & $-0.7(-1.1 ;-0.2)$ \\
\hline Fruit and vegetables consumption $<400 \mathrm{~g} / \mathrm{day}$ & $-3.0(-4.2 ;-1.8)$ & $-1.6(-2.3 ;-1.0)$ & $-2.4(-3.7 ;-1.1)$ & $-1.3(-2.0 ;-0.5)$ \\
\hline Fruit and vegetables consumption $\geq 400 \mathrm{~g} / \mathrm{day}$ & $-1.7(-2.4 ;-1.0)$ & $-0.8(-1.1 ;-0.5)$ & $-1.3(-2.0 ;-0.5)$ & $-0.6(-1.0 ;-0.2)$ \\
\hline Low adherence to the mPNNS-GS & $-3.3(-4.6 ;-2.0)$ & $-1.5(-2.1 ;-0.9)$ & $-2.7(-4.1 ;-1.3)$ & $-1.2(-1.8 ;-0.5)$ \\
\hline Medium adherence to the mPNNS-GS & $-2.0(-2.9 ;-1.2)$ & $-1.7(-2.3 ;-1.0)$ & $-1.6(-2.5 ;-0.7)$ & $-1.3(-2.0 ;-0.5)$ \\
\hline High adherence to the mPNNS-GS & $-2.4(-3.3 ;-1.4)$ & $-1.1(-1.5 ;-0.7)$ & $-1.9(-2.9 ;-0.9)$ & $-0.8(-1.3 ;-0.3)$ \\
\hline Low adherence to the MEDI-LITE & $-3.0(-4.2 ;-1.8)$ & $-1.5(-2.2 ;-0.9)$ & $-2.4(-3.7 ;-1.2)$ & $-1.2(-1.9 ;-0.5)$ \\
\hline Medium adherence to the MEDI-LITE & $-2.9(-4.0 ;-1.7)$ & $-1.4(-2.0 ;-0.9)$ & $-2.3(-3.5 ;-1.0)$ & $-1.1(-1.8 ;-0.4)$ \\
\hline High adherence to the MEDI-LITE & $-1.9(-2.8 ;-1.1)$ & $-1.1(-1.6 ;-0.6)$ & $-1.6(-2.4 ;-0.7)$ & $-0.9(-1.4 ;-0.4)$ \\
\hline Low adherence to the provegetarian FP & $-2.9(-4.0 ;-1.7)$ & $-1.5(-2.1 ;-0.9)$ & $-2.3(-3.5 ;-1.1)$ & $-1.1(-1.8 ;-0.5)$ \\
\hline Medium adherence to the provegetarian FP & $-2.6(-3.7 ;-1.6)$ & $-1.3(-1.8 ;-0.7)$ & $-2.1(-3.2 ;-1.0)$ & $-1.0(-1.6 ;-0.4)$ \\
\hline High adherence to the provegetarian FP & $-2.3(-3.2 ;-1.3)$ & $-1.4(-1.9 ;-0.8)$ & $-1.8(-2.8 ;-0.8)$ & $-1.1(-1.7 ;-0.4)$ \\
\hline \multicolumn{5}{|c|}{ Spring rolls } \\
\hline Whole population & $-2.1(-3.3 ;-0.8)$ & $-1.2(-1.8 ;-0.5)$ & $-5.1(-7.3 ;-2.4)$ & $-2.9(-4.5 ;-1.0)$ \\
\hline Pizza consumers & $-5.2(-8.1 ;-2.1)$ & $-3.6(-5.6 ;-1.6)$ & $-11.4(-16.9 ;-4.6)$ & $-8.3(-12.9 ;-2.4)$ \\
\hline Participants who consumed pizza once & $-4.0(-6.2 ;-1.6)$ & $-3.1(-4.8 ;-1.4)$ & $-8.9(-13.1 ;-3.9)$ & $-7.4(-11.3 ;-2.4)$ \\
\hline Participants who consumed pizza twice & $-7.6(-11.7 ;-3.1)$ & $-5.1(-7.9 ;-2.2)$ & $-15.0(-23.1 ;-4.8)$ & $-8.9(-16.6 ; 0.2)$ \\
\hline Participants who consumed pizza more than twice & $-11.0(-16.8 ;-4.5)$ & $-8.4(-12.9 ;-3.7)$ & $-21.6(-32.9 ;-6.0)$ & $-19.5(-29.0 ;-6.3)$ \\
\hline Age $<45$ years & $-3.2(-5.0 ;-1.3)$ & $-1.6(-2.4 ;-0.7)$ & $-6.8(-10.6 ;-2.2)$ & $-3.1(-5.6 ;-0.3)$ \\
\hline Age $\geq 45$ years & $-1.1(-1.8 ;-0.5)$ & $-0.7(-1.1 ;-0.3)$ & $-3.0(-4.0 ;-1.7)$ & $-2.0(-2.8 ;-1.0)$ \\
\hline Body mass index $<25$ & $-2.6(-4.0 ;-1.0)$ & $-1.3(-2.0 ;-0.6)$ & $-2.4(-6.4 ; 1.9)$ & $-1.1(-3.5 ; 1.5)$ \\
\hline Body mass index $\geq 25$ & $-1.7(-2.6 ;-0.7)$ & $-0.9(-1.5 ;-0.4)$ & $-5.2(-6.5 ;-3.9)$ & $-3.6(-4.3 ;-2.7)$ \\
\hline Fruit and vegetables consumption $<400 \mathrm{~g} /$ day & $-2.3(-3.7 ;-0.9)$ & $-1.3(-2.1 ;-0.6)$ & $-5.6(-8.2 ;-2.5)$ & $-3.4(-5.2 ;-1.1)$ \\
\hline Fruit and vegetables consumption $\geq 400 \mathrm{~g} / \mathrm{day}$ & $-1.5(-2.3 ;-0.6)$ & $-0.8(-1.1 ;-0.3)$ & $-3.6(-5.0 ;-2.0)$ & $-1.8(-2.8 ;-0.7)$ \\
\hline Low adherence to the mPNNS-GS & $-2.6(-4.0 ;-1.0)$ & $-1.2(-1.8 ;-0.5)$ & $-6.0(-8.9 ;-2.4)$ & $-2.8(-4.5 ;-0.7)$ \\
\hline Medium adherence to the mPNNS-GS & $-1.7(-2.6 ;-0.7)$ & $-1.4(-2.1 ;-0.6)$ & $-4.2(-5.9 ;-2.2)$ & $-3.4(-5.3 ;-1.1)$ \\
\hline High adherence to the mPNNS-GS & $-2.0(-3.1 ;-0.8)$ & $-1.0(-1.6 ;-0.5)$ & $-4.7(-6.7 ;-2.3)$ & $-2.6(-3.7 ;-1.1)$ \\
\hline Low adherence to the MEDI-LITE & $-2.3(-3.6 ;-0.9)$ & $-1.2(-1.9 ;-0.5)$ & $-5.6(-8.2 ;-2.5)$ & $-3.5(-5.0 ;-1.4)$ \\
\hline Medium adherence to the MEDI-LITE & $-2.4(-3.7 ;-1.0)$ & $-1.3(-2.0 ;-0.6)$ & $-5.7(-8.1 ;-2.9)$ & $-2.9(-4.6 ;-0.9)$ \\
\hline High adherence to the MEDI-LITE & $-1.7(-2.6 ;-0.7)$ & $-1.1(-1.6 ;-0.5)$ & $-4.0(-5.7 ;-2.0)$ & $-2.3(-3.6 ;-0.7)$ \\
\hline Low adherence to the provegetarian FP & $-2.2(-3.5 ;-0.8)$ & $-1.2(-1.9 ;-0.5)$ & $-5.5(-8.0 ;-2.6)$ & $-3.2(-4.9 ;-1.1)$ \\
\hline Medium adherence to the provegetarian FP & $-2.1(-3.3 ;-0.8)$ & $-1.1(-1.7 ;-0.5)$ & $-5.3(-7.5 ;-2.6)$ & $-2.8(-4.2 ;-1.1)$ \\
\hline High adherence to the provegetarian FP & $-2.0(-3.1 ;-0.9)$ & $-1.3(-1.9 ;-0.6)$ & $-4.4(-6.4 ;-2.1)$ & $-2.6(-4.2 ;-0.7)$ \\
\hline \multicolumn{5}{|c|}{ Spaghetti with tomato sauce } \\
\hline Whole population & $-1.1(-1.5 ;-0.6)$ & $-0.7(-0.9 ;-0.4)$ & $-5.4(-8.1 ;-1.8)$ & $-3.2(-5.3 ;-0.6)$ \\
\hline Pizza consumers & $-2.7(-3.9 ;-1.4)$ & $-2.2(-2.9 ;-1.4)$ & $-11.4(-18.4 ;-2.0)$ & $-8.7(-15.0 ;-0.6)$ \\
\hline Participants who consumed pizza once & $-2.1(-3.0 ;-1.1)$ & $-1.9(-2.5 ;-1.2)$ & $-9.1(-14.3 ;-2.2)$ & $-7.9(-13.1 ;-1.0)$ \\
\hline Participants who consumed pizza twice & $-3.9(-5.7 ;-2.0)$ & $-2.9(-4.0 ;-1.8)$ & $-13.9(-24.6 ; 0.6)$ & $-8.1(-18.6 ; 4.7)$ \\
\hline Participants who consumed pizza more than twice & $-5.7(-8.2 ;-3.1)$ & $-4.9(-6.8 ;-3.0)$ & $-19.7(-34.9 ; 2.4)$ & $-20.0(-32.4 ;-1.7)$ \\
\hline Age $<45$ years & $-1.6(-2.3 ;-0.8)$ & $-0.9(-1.2 ;-0.6)$ & $-6.7(-11.6 ;-0.5)$ & $-3.2(-6.5 ; 0.8)$ \\
\hline Age $\geq 45$ years & $-0.6(-0.9 ;-0.4)$ & $-0.5(-0.7 ;-0.3)$ & $-3.3(-4.6 ;-1.7)$ & $-2.3(-3.3 ;-0.9)$ \\
\hline Body mass index $<25$ & $-1.3(-1.9 ;-0.7)$ & $-0.8(-1.1 ;-0.5)$ & $-1.0(-6.5 ; 5.0)$ & $-0.5(-3.9 ; 3.2)$ \\
\hline
\end{tabular}




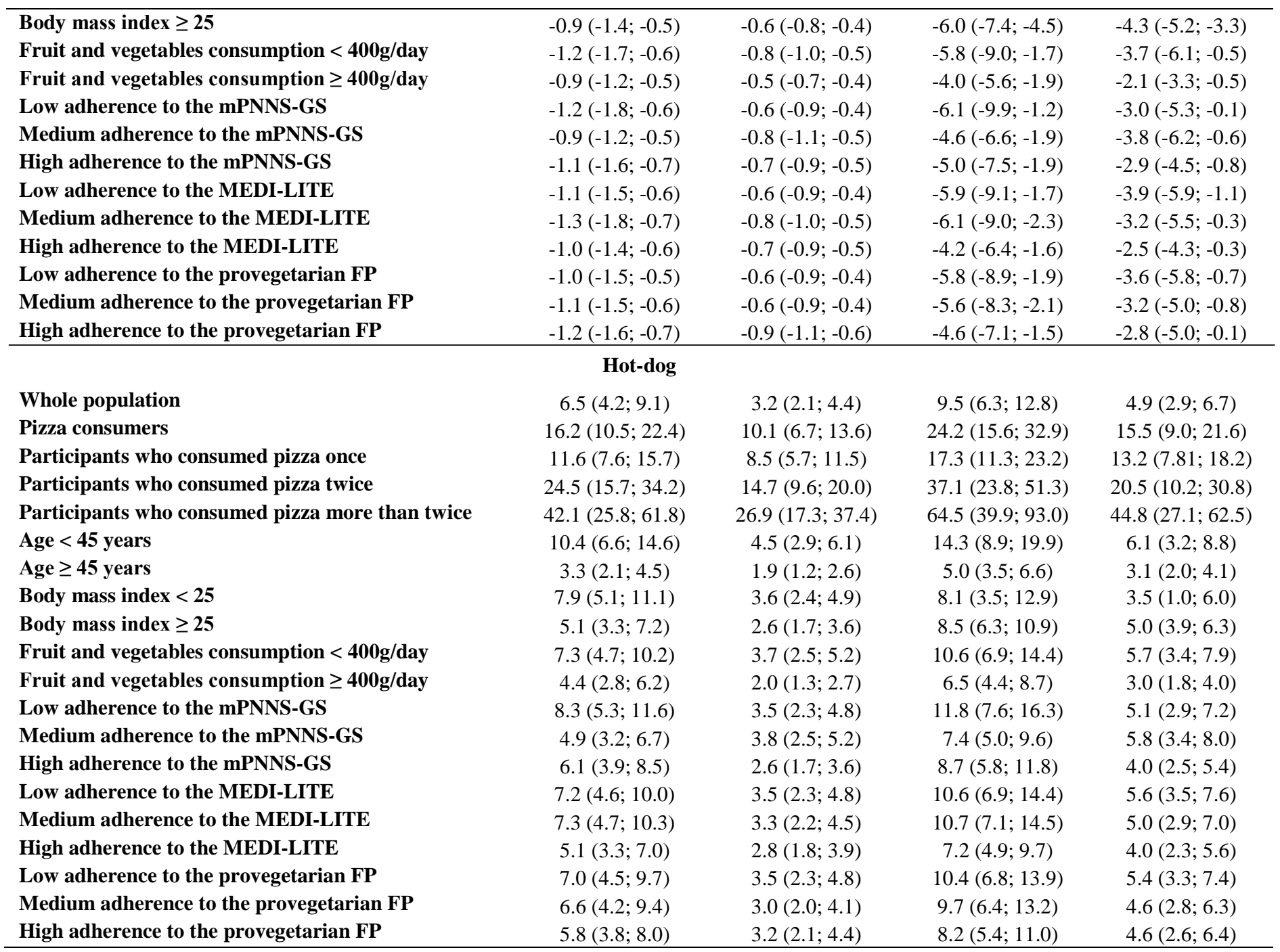

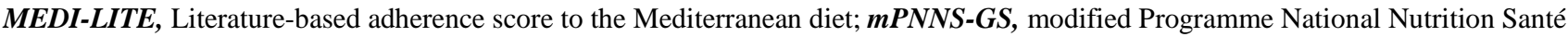
Guideline Score; NIE substitution, Non-isoenergetic substitution; Provegetarian FP, Provegetarian food pattern

$\dagger$ Results are the observed risk variations for the best and worst mixed dishes identified for isoenergetic and non-isoenergetic substitutions. 
STROBE Statement—checklist of items that should be included in reports of observational studies

\begin{tabular}{|c|c|c|c|}
\hline & $\begin{array}{l}\text { Item } \\
\text { No }\end{array}$ & Recommendation & Page number \\
\hline \multirow[t]{2}{*}{ Title and abstract } & \multirow[t]{2}{*}{1} & $\begin{array}{l}\text { (a) Indicate the study's design with a commonly used term in the title or the } \\
\text { abstract }\end{array}$ & 1,3 \\
\hline & & $\begin{array}{l}\text { (b) Provide in the abstract an informative and balanced summary of what } \\
\text { was done and what was found }\end{array}$ & 3 \\
\hline \multicolumn{4}{|l|}{ Introduction } \\
\hline Background/rationale & 2 & $\begin{array}{l}\text { Explain the scientific background and rationale for the investigation being } \\
\text { reported }\end{array}$ & 4 \\
\hline Objectives & 3 & State specific objectives, including any prespecified hypotheses & 4,5 \\
\hline \multicolumn{4}{|l|}{ Methods } \\
\hline Study design & 4 & Present key elements of study design early in the paper & $5-9$ \\
\hline Setting & 5 & $\begin{array}{l}\text { Describe the setting, locations, and relevant dates, including periods of } \\
\text { recruitment, exposure, follow-up, and data collection }\end{array}$ & $5-9$ \\
\hline \multirow[t]{2}{*}{ Participants } & \multirow[t]{2}{*}{6} & $\begin{array}{l}\text { (a) Cohort study_-Give the eligibility criteria, and the sources and methods } \\
\text { of selection of participants. Describe methods of follow-up } \\
\text { Case-control study_-Give the eligibility criteria, and the sources and } \\
\text { methods of case ascertainment and control selection. Give the rationale for } \\
\text { the choice of cases and controls } \\
\text { Cross-sectional study - Give the eligibility criteria, and the sources and } \\
\text { methods of selection of participants }\end{array}$ & $5-6$ \\
\hline & & $\begin{array}{l}\text { (b) Cohort study_-For matched studies, give matching criteria and number } \\
\text { of exposed and unexposed } \\
\text { Case-control study-For matched studies, give matching criteria and the } \\
\text { number of controls per case }\end{array}$ & \\
\hline Variables & 7 & $\begin{array}{l}\text { Clearly define all outcomes, exposures, predictors, potential confounders, } \\
\text { and effect modifiers. Give diagnostic criteria, if applicable }\end{array}$ & $5-9$ \\
\hline $\begin{array}{l}\text { Data sources/ } \\
\text { measurement }\end{array}$ & $8^{*}$ & $\begin{array}{l}\text { For each variable of interest, give sources of data and details of methods of } \\
\text { assessment (measurement). Describe comparability of assessment methods } \\
\text { if there is more than one group }\end{array}$ & $\begin{array}{l}\text { 5-9; eFigures } 3 \text {, } \\
\text { eTables } 1-2\end{array}$ \\
\hline Bias & 9 & Describe any efforts to address potential sources of bias & \\
\hline Study size & 10 & Explain how the study size was arrived at & 5-6; eFigures 1 \\
\hline $\begin{array}{l}\text { Quantitative } \\
\text { variables }\end{array}$ & 11 & $\begin{array}{l}\text { Explain how quantitative variables were handled in the analyses. If } \\
\text { applicable, describe which groupings were chosen and why }\end{array}$ & \\
\hline \multirow[t]{6}{*}{ Statistical methods } & \multirow[t]{6}{*}{12} & $\begin{array}{l}\text { (a) Describe all statistical methods, including those used to control for } \\
\text { confounding }\end{array}$ & 5-9; eFigures 2 \\
\hline & & (b) Describe any methods used to examine subgroups and interactions & $6-9$ \\
\hline & & (c) Explain how missing data were addressed & \\
\hline & & $\begin{array}{l}\text { (d) Cohort study-If applicable, explain how loss to follow-up was } \\
\text { addressed }\end{array}$ & eFigures 1 \\
\hline & & $\begin{array}{l}\text { Case-control study - If applicable, explain how matching of cases and } \\
\text { controls was addressed }\end{array}$ & \\
\hline & & $\begin{array}{l}\text { Cross-sectional study-If applicable, describe analytical methods taking } \\
\text { account of sampling strategy }\end{array}$ & \\
\hline
\end{tabular}

(e) Describe any sensitivity analyses 
Results

\begin{tabular}{|c|c|c|c|}
\hline \multirow[t]{3}{*}{ Participants } & $13^{*}$ & $\begin{array}{l}\text { (a) Report numbers of individuals at each stage of study—eg numbers } \\
\text { potentially eligible, examined for eligibility, confirmed eligible, included in } \\
\text { the study, completing follow-up, and analysed }\end{array}$ & 5; eFigures 1 \\
\hline & & (b) Give reasons for non-participation at each stage & 5; eFigures 1 \\
\hline & & (c) Consider use of a flow diagram & eFigures 1 \\
\hline $\begin{array}{l}\text { Descriptive } \\
\text { data }\end{array}$ & $14^{*}$ & $\begin{array}{l}\text { (a) Give characteristics of study participants (eg demographic, clinical, } \\
\text { social) and information on exposures and potential confounders }\end{array}$ & 9; Table 1 \\
\hline
\end{tabular}

(b) Indicate number of participants with missing data for each variable of interest

(c) Cohort study-Summarise follow-up time (eg, average and total amount)

\begin{tabular}{ll}
\hline Outcome data $15^{*}$ & $\begin{array}{l}\text { Cohort study—Report numbers of outcome events or summary measures } \\
\text { over time }\end{array}$ \\
& $\begin{array}{l}\text { Case-control study—Report numbers in each exposure category, or summary } \\
\text { measures of exposure }\end{array}$ \\
& $\begin{array}{l}\text { Cross-sectional study—Report numbers of outcome events or summary } \\
\text { measures }\end{array}$ \\
\hline
\end{tabular}

\begin{tabular}{lrll}
\hline Main results & 16 & $\begin{array}{l}\text { (a) Give unadjusted estimates and, if applicable, confounder-adjusted } \\
\text { estimates and their precision (eg, 95\% confidence interval). Make clear which } \\
\text { confounders were adjusted for and why they were included }\end{array}$ & $\begin{array}{l}\text { 9-10; Table 2; } \\
\text { Figure 1 }\end{array}$ \\
\cline { 3 - 4 } & & $\begin{array}{l}\text { (b) Report category boundaries when continuous variables were categorized } \\
\text { (c) If relevant, consider translating estimates of relative risk into absolute risk } \\
\text { for a meaningful time period }\end{array}$ & \\
\hline Other analyses & 17 & $\begin{array}{l}\text { Report other analyses done-eg analyses of subgroups and interactions, and } \\
\text { sensitivity analyses }\end{array}$ & $\begin{array}{l}\text { 10-11; Table 2; } \\
\text { eTables 3-4; } \\
\end{array}$ \\
& & Figure 2 \\
\hline
\end{tabular}

\begin{tabular}{llll}
\hline Discussion & & & \\
\hline Key results & 18 & Summarise key results with reference to study objectives & 11 \\
\hline Limitations & 19 & $\begin{array}{l}\text { Discuss limitations of the study, taking into account sources of potential bias } \\
\text { or imprecision. Discuss both direction and magnitude of any potential bias }\end{array}$ & 14 \\
\hline Interpretation & 20 & $\begin{array}{l}\text { Give a cautious overall interpretation of results considering objectives, } \\
\text { limitations, multiplicity of analyses, results from similar studies, and other } \\
\text { relevant evidence }\end{array}$ & $13-15$ \\
\hline Generalisability & 21 & Discuss the generalisability (external validity) of the study results & \\
\hline
\end{tabular}

\section{Other information}

Funding 22 Give the source of funding and the role of the funders for the present study
and, if applicable, for the original study on which the present article is based

*Give information separately for cases and controls in case-control studies and, if applicable, for exposed and unexposed groups in cohort and cross-sectional studies.

\section{Manuscript: Impact of intra-category food substitutions on the risk of type 2 diabetes: a modelling study on the pizza category}

